Policy Research Working Paper 2273

The Value of Preventing Malaria in Tembien, Ethiopia

Maureen L. Cropper

Mitıku Halle

Julian A. Lampietti

Christme Poulos

Dale Whattington
Despite the great benefits

from preventing malaria, the fact that vaccine demand is price inelastic suggests that it will be difficult to achieve significant market

penetration unless the vaccine is subsidized. The results are similar for bed nets treated with insecticide

The World Bank

Development Research Group Infrastructure and Environment January 2000 
Policy Research Working Paper 2273

\section{Summary findings}

Cropper, Haile, Lampietti, Poulos, and Whittington measure the monetary value households place on preventing malaria in Tembien, Tigray Region, Ethiopia. They estimate a household demand function for a hypothetical malaria vaccine and compute the value of preventing malaria as the household's maximum willingness to pay to provide vaccines for all family members. They contrast willingness to pay with the traditional costs of illness (medical costs and time lost because of malaria).

Their results indicate that the value of preventing malaria with vaccines is about US\$36 a household a year, or about 15 percent of imputed annual household income. This is, on average, about two or three times the expected household cost of illness.

Despite the great benefits from preventing malaria, the fact that vaccine demand is price inelastic suggests that it will be difficult to achieve significant market penetration unless the vaccine is subsidized.

The authors obtain similar results for insecticidetreated bed nets. Their estimates of household demand functions for bed nets suggest that at a price that might permit cost recovery (US $\$ 6$ a bed net), only a third of the population of a 200 -person village would sleep under bed nets.

This paper - a product of Infrastructure and Environment, Development Research Group - is part of a larger effort in the group to promote efficient resource allocation within the health sector. Copies of the paper are available free from the World Bank, 1818 H Street, NW, Washington, DC 20433. Please contact Tourya Tourougui, room MC2-521, telephone 202-458-7431, fax 202-522-3230, email address ttourougui@worldbank.org. Policy Research Working Papers are also posted on the Web at www.worldbank.org/research/workingpapers. The authors may be contacted at mcropper @worldbank.org, jlampietti@worldbank.org, cpoulos@email.unc.edu, or dwhittin@imap.unc.edu. January 2000.(75 pages)

The Policy Research Working Paper Series disseminates the findings of work in progress to encourage the exchange of ideas about development issues. An objective of the series is to get the findings out quickly, even if the presentations are less than fully polished. The papers carry the names of the authors and should be cited accordingly. The findings, interpretations, and conclusions expressed in this paper are entirely those of the authors. They do not necessarily represent the view of the World Bank, its Executive Directors, or the countries they represent. 


\title{
THE VALUE OF PREVENTING MALARIA IN TEMBIEN, ETHIOPIA
}

\author{
By Maureen L. Cropper, Mitiku Haile, Julian A. Lampietti, \\ Christine Poulos, and Dale Whittington
}

Corresponding Author:

Maureen L. Cropper

The World Bank,

1818 H. Street, Washington, DC, 20433

Email: mcropper@worldbank.org

The findings, interpretations, and conclusions expressed in this paper are entirely those of the authors. They do not necessarily represent the views of the World Bank, its Executive Directors, or the countries they represent, nor do they represent the views of the World Health Organization. 


\section{SUMMARY}

This study measures the monetary value households place on preventing malaria in Tigray, Ethiopia. We estimate a household demand function for a hypothetical malaria vaccine and calculate willingness to pay to prevent malaria as the area beneath this demand function to the left of household size. Willingness to pay is contrasted with the traditional costs of illness--the medical costs and time lost due to malaria.

Our results indicate that the value of preventing malaria with vaccines is about 36 USD per household per year or about 15 percent of imputed annual household income. This is, on average, about two or three times the expected household cost of illness. While the benefits from preventing malaria are large, the fact that vaccine demand is price inelastic suggests that it will be difficult to achieve significant market penetration unless the vaccine is subsidized.

Similar results are obtained for insecticide-treated bednets. Our estimates of household demand functions for bednets suggest that at a price that might permit cost recovery (6 USD per bednet), only one-third of the population of a 200-person village would sleep under bednets. 


\section{ACKNOWLEDGEMENTS}

The School of Public Health at the University of North Carolina received financial support from the UNDP/World Bank/WHO Special Programme for Research and Training in Tropical Disease. The authors would like to thank M. Gomes for comments and Bill Evans for providing the SAS code used to estimate the multivariate model. Carol Jenkins conducted the initial ethnographic survey. The field work would not have been possible without the help of K. Komives, Zarai, Amare Belay, Gebremedhin Woldewahid, Gebremichael and the members of the enumeration teams. Special thanks are also due to $T$. Ghebreyesus and the Tigray Malaria Control Office and to staff at University College Mekelle. 



\section{CONTENTS}

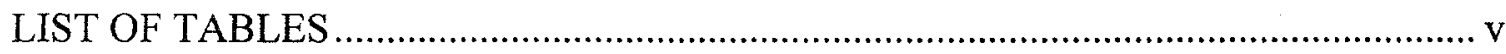

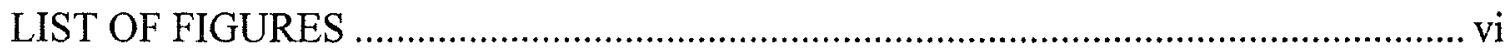

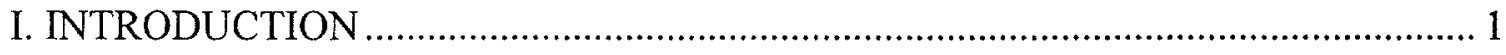

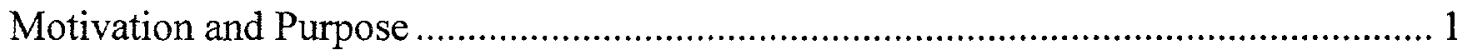

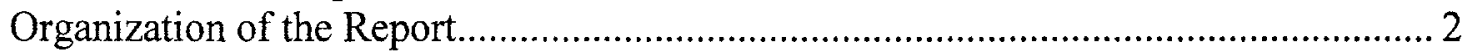

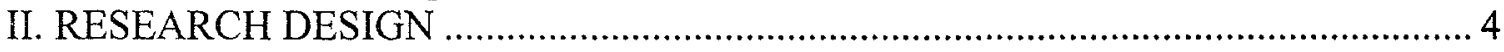

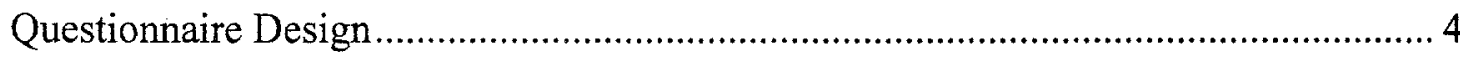

Cost of Illness Questions ........................................................................................ 4

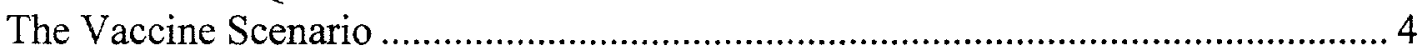

The Bednet Scenario …………………................................................................. 5

Choice of Study Area and Villages........................................................................... 5

Characteristics of the Sample Population ................................................................... 6

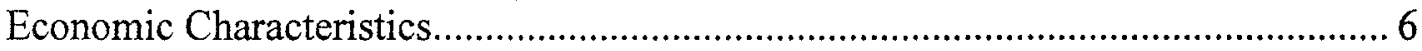

Family Composition and Education..........................................................................

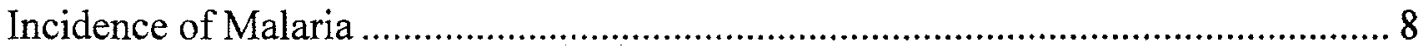

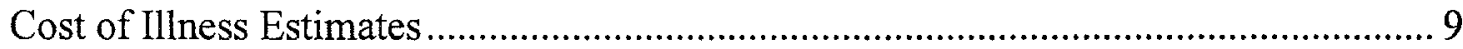

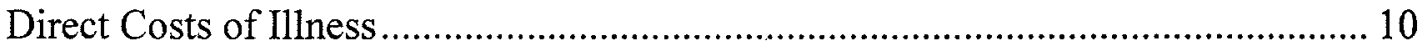

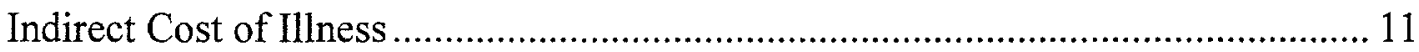

Total COI per Episode …………………............................................................... 12

Household Demand for a Malaria Vaccine............................................................. 12

A Model of the Demand for Health-Related Goods ................................................. 13

Applicability of the Model to Northern Ethiopia......................................................... 14

Willingness to Pay for Malaria Prevention............................................................... 15

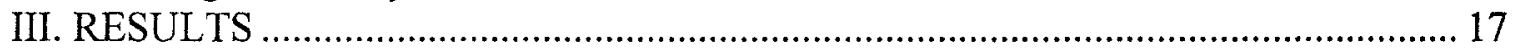

Empirical Analysis of Vaccine Demand .................................................................... 17

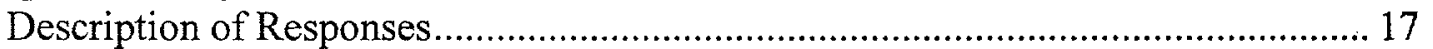

Estimation of Household Demand Functions ............................................................ 17

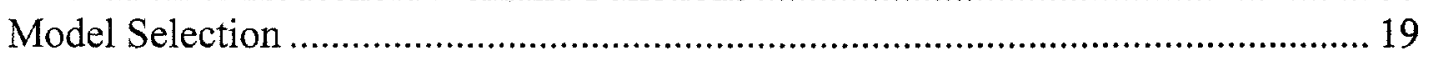

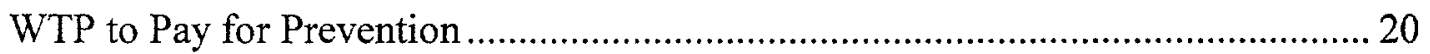

Comparison of Willingness to Pay and Cost of Illness.................................................. 20

Expected COI Based on Average Sample Experience …………………………..... 21

Household Demand for Bednets ............................................................................ 22

Estimation of Household Demand Functions for Bednets........................................ 23

Willingness to Pay for Bednets............................................................................... 24

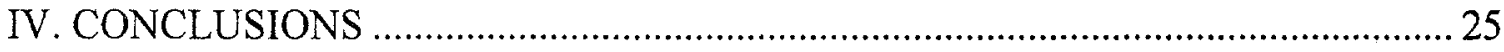

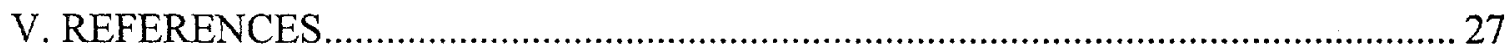

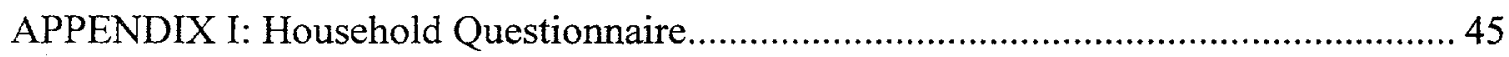

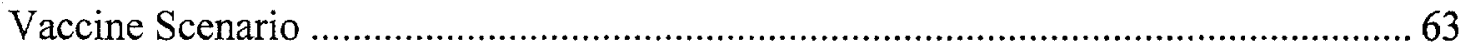

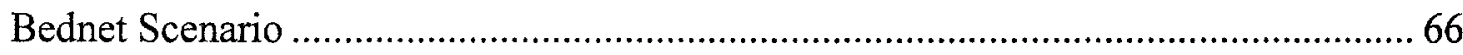

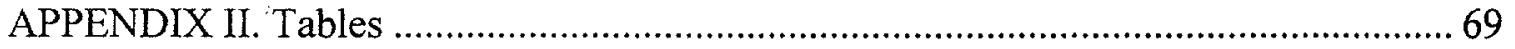




\section{LIST OF TABLES}

Table 1. Number of Households Receiving Each Version of Questionnaire (n; column percent) 29

Table 2. Mean Value of Livestock for Households Who Own Livestock (Birr*).......... 29

Table 3. Household Demographic Characteristics........................................................... 30

Table 4. Household Malaria Incidence (in last 2 years unless otherwise specified) ......... 30

Table 5. Elements of Direct Cost of Illness per Episode, Sample Averages by Age Group

Table 6. Productivity Losses Per Malaria Episode, by Age Group (Average Number of Days)

Table 7. Average Cost of Illness Per Episode, Using High and Low Productivity Assumptions 32

Table 8. Average Annual Cost of Illness Per Household, Using Actual Illness ( $\mathrm{n}=848$ ) 33

Table 9. Number of Hypothetical Vaccines Purchased by Price 33

Table 10. Coverage with Vaccines by Income Group and Demographic Category ........ 33

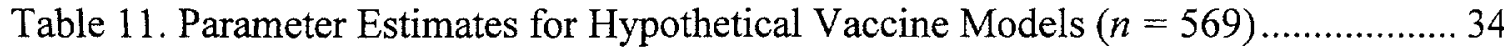

Table 12. Goodness of Fit Criteria for Hypothetical Vaccine Model .............................. 35

Table 13. Willingness to Pay for Hypothetical Vaccine $(n=569) \ldots \ldots \ldots \ldots \ldots \ldots \ldots \ldots \ldots \ldots \ldots \ldots . . . . .35$

Table 14. Average Annual Cost of Illness Per Household Using Sample Illness

Frequencies to Predict Future Illness and Average Per Episode COI (Entire Sample)

Table 15. Ratios of Three Estimates of WTP for Malaria Vaccine to Two estimates of

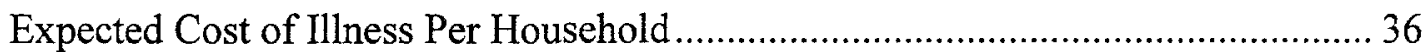

Table 16. Number of Bednets Purchased by Price …………......................................... 36

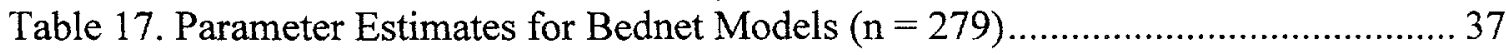

Table 18. Goodness of Fit Criteria for Bednets ......................................................... 38

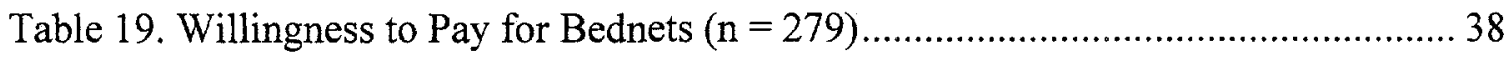




\section{LIST OF FIGURES}

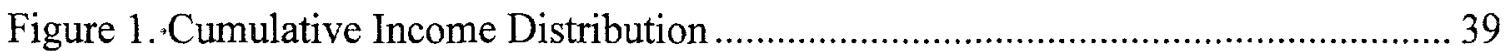

Figure 2. Lorenz Curve for Household Income ............................................................ 39

Figure 3. Household Demand Curve for Vaccines and WTP for Total Prevention ......... 40

Figure 4. Number of Hypothetical Vaccines Purchased by Price ..................................... 40

Figure 5. Malaria Vaccine Demand For 200 Household Village in Tigray, Ethiopia...... 41

Figure 6. Percent of Income Spent on Vaccines at Different Prices in Tigray, Ethiopia . 41

Figure 7. Distribution of Household WTP for Vaccines ................................................. 42

Figure 8. Probability of Purchasing Bednets at Different Prices ...................................... 42

Figure 9. Demand for Bednets in 200 Household Village in Tigray, Ethiopia ................ 43 



\section{INTRODUCTION}

\section{Motivation and Purpose}

The purpose of this study is to measure the monetary value households place on preventing malaria in Tigray, a region in the north of Ethiopia. To persons familiar with malaria, the value of preventing it might seem self-evident. There are, however, at least two reasons why it is important to attach a dollar value to reductions in the disease (Gomes, 1993). The first is that, both within the health sector and outside of that sector, malaria prevention programs must compete with other programs for funds. Unless one can attach a dollar value to the benefits of preventing malaria, it is difficult for malaria prevention programs to be compared with other programs whose benefits are more easily monetized and to compete with them for funding. The second reason is that, in order to design and implement malaria prevention programs, it is necessary to measure what people are willing to pay for them.

To elaborate on the first point, the value of preventing malaria has typically been equated with the economic losses ("costs of illness") associated with the disease- the value of lost productivity plus medical costs. Economic losses, however, fail to capture the pain and suffering associated with malaria, and tend to place a low value on preventing the disease in children and the elderly. Previous studies suggest that the value of preventing malaria-what people are willing to pay to prevent the disease-may be larger than the economic losses associated with malaria (Whittington et al., 1996). We examine this rigorously to determine whether the private benefits of malaria control programs are larger than previously thought.

The first goal of our research is to measure what people in the Tigray region of Ethiopia would pay to prevent malaria in their households, and to contrast these estimates with the economic losses associated with malaria in the region. In order to measure what a household in Tigray would pay to prevent malaria we asked the household head (or spouse) whether he or she would purchase hypothetical malaria vaccines for persons in the family, at a stated price. The advantage of using a hypothetical vaccine is that it should capture all components of a household's willingness to pay to prevent malaria. In 
the health economics literature, the value of avoiding illness is the sum of the various categories of damages associated with illness. Morbidity (1) reduces the time that a household spends on productive activities; (2) may necessitate medical expenditures; (3) may reduce leisure time; (4) may lead to expenditures to prevent illness; and (5) often yields disutility because of the pain and inconvenience it causes. If a respondent could purchase a vaccine that would prevent a household member from contracting malaria, the household could avoid all five components of the damages associated with morbidity from malaria. The vaccine would also eliminate risk of death from the disease.

Household demand for a hypothetical vaccine thus captures all components of the value of avoiding malaria.

A second goal of the research is to compare the value of avoiding malaria with the traditional costs of illness, which capture only components (1) and (2) of the morbidity damages caused by illness. In order to compare the two measures, we asked people to recall the most recent malaria episode that (a) they experienced, and (b) that one of their children experienced, and then elicited the various components of the cost of illness.

A third goal of the research is to estimate what people would pay for an actual malaria prevention program - the use of impregnated bednets. Knowing what fraction of a population would purchase bednets at various prices is essential to the design of a bednet control program. In designing such a program one must balance the goals of cost recovery - which is necessary for a program to be self-sustaining-against the arguments for government subsidization of the program because of the externalities associated with the control of infectious disease. Knowing what percent of the population would purchase bednets at prices in the neighborhood of replacement cost allows a policy maker to calculate how large the bednet subsidy must be in order to ensure participation in such a program of any desired fraction of the population.

\section{Organization of the Report}

The remainder of this report has three parts. Part II (Research Design) begins with a description of the questionnaire design and the study area. It then describes the characteristics of the study population and their experience with malaria. We go on to calculate the costs of illness associated with the disease. This is followed by a formal model of a household's demand for a good (e.g., a vaccine or a bednet) that reduces time 
spent ill with malaria. We use this model to derive an expression for a household's willingness to pay (WTP) to prevent malaria, which could be accomplished by purchasing vaccines for all family members. This model also yields an expression for the costs of illness (COI). Part III of the report contains empirical estimates of household demand functions for vaccines and for bednets. We present estimates of a household demand function for a malaria vaccine and use it to calculate WTP for malaria prevention. We then contrast these values with the traditional costs of illness. This section concludes with estimates of the demand for insecticide-treated bednets. Part IV of the report summarizes our findings and offers some concluding remarks. 


\section{RESEARCH DESIGN}

\section{Questionnaire Design}

A three-part survey instrument was developed to measure both the COI associated with malaria and WTP for malaria prevention. (The questionnaire is contained in APPENDIX I.) ${ }^{1}$ The first part of the survey asked questions about a household's current health status, knowledge of malaria, and past expenditures on malaria prevention and treatment. The second part presented the respondent with one of two contingent valuation scenarios--a hypothetical vaccine scenario or a bednet scenario. The third section of the questionnaire requested information on the socioeconomic characteristics of the household members, including education, income, assets, occupation, and housing construction.

Cost of Illness Questions

To measure COI, respondents were asked a series of questions about their most recent episode of malaria during the last two years. This included questions about the length and severity of the illness as well as questions about treatment sought and the costs of treatment. It also included questions about the time others spent caring for the respondent when he was ill and about intra-household labor substitution in response to the respondent's lost work time. Similarly, to measure COI for children and teenagers, respondents were asked about the most recent malaria episode experienced within the last two years by either a child or a teenager in the household. This was followed by questions about treatment, treatment costs, caretakers' time, and intra-household labor substitution.

\section{The Vaccine Scenario}

The hypothetical vaccine scenario began by emphasizing that such a vaccine is not currently and might never be available. The enumerator described a hypothetical vaccine to the respondent, available as either a pill or injection, which would prevent the recipient from contracting malaria for one year. The scenario checked respondent

\footnotetext{
${ }^{1}$ The questionnaire, translated into Tigrigna, was pretested prior to administration. The questionnaire was back-translated into English by a second interpreter to check for inconsistencies and inaccuracies in the local language version of the survey instrument. A summary of responses to the questionnaire is available from the authors upon request.
} 
understanding of the benefits of the vaccine, and provided reminders of substitute goods and the budget constraint. It was also emphasized that a separate vaccine would need to be purchased for each member of the household in order to protect them from getting malaria for one year. The respondent was asked whether he would purchase one or more hypothetical vaccines at one of five randomly assigned prices. The lowest price was Birr 5 ( 0.8 USD) and the highest price Birr 200 (32 USD). ${ }^{2}$ If the respondent answered 'yes' to the original choice question, he was then asked how many hypothetical vaccines would be purchased and to whom they would be given (e.g. adults, teenagers, children).

\section{The Bednet Scenario}

A separate sample of respondents received an insecticide-treated bednet (ITN) contingent valuation scenario. The bednet scenario coupled an explanation of how using a bednet reduces the probability of contracting malaria with an actual demonstration of a double-size polyester bednet impregnated with 1 percent Deltamethrin. This scenario also checked respondent understanding of how the bednet works, and provided reminders of substitute goods and budget constraints. Respondents were then presented with information about the costs of annual re-impregnation of an ITN over its 4-year expected life and were told that they could spread payments for the bednets over 4 months.

The respondent was offered the opportunity to purchase one or more bednets at one of five randomly assigned prices. Prices per bednet ranged from a low of Birr 8 (1.3 USD) to a high of Birr 100 (16 USD), with Birr 40 (6.4 USD) as the middle price. The highest price, which is lower than the highest price charged for the hypothetical vaccine, is based on an estimate of the maximum amount that one could conceivably charge for full cost recovery of an imported ITN. As with the hypothetical vaccine scenario, if the respondent answered 'yes' to this choice question, he was asked how many bednets would be purchased and for whom in the household they would be used (e.g. adults, teenagers, and children).

\section{Choice of Study Area and Villages}

Our survey was conducted in January of 1997. It was administered by 18 local interviewers, all of whom were secondary school graduates. Interviewers received two

\footnotetext{
${ }^{2}$ IUSD $=$ Birr 6.3
} 
weeks of training in survey administration from the authors, with the help of local translators. The interviewers were directed by three field supervisors, who were affiliated with Mekelle College.

The survey was conducted in the Tembien sector of Tigray region in northern Ethiopia. We selected two districts (Tangua Abergelle and Kola Tembien) and then chose 18 villages in the 2 districts. The choice of villages was designed to provide some variation in malaria incidence. Because no official statistics on incidence were available, we used information on chloroquine distribution and village altitude as proxies for incidence. Chloroquine is the most widely used treatment for malaria in Tigray and figures on distribution are available from the Tigray Regional Malaria Control District. Mosquitoes are more likely to be present at lower than at higher altitudes, so villages were selected at altitudes varying from 1,000 to 2,000 meters. Twelve of the villages received the vaccine scenario and six the bednet scenario:

Our goal was to interview 50 households in each of the 18 study villages. Random sampling within each village was difficult because up-to-date household lists did not exist. Each interviewer was placed at a different location in the village and instructed to walk in a specified direction, interviewing every other household. To simplify the logistics of the fieldwork and to avoid spreading confusion in a village when respondents talked to one another, all households in the same village received the same scenario (vaccines or bednets).

A total of 889 field interviews were completed; however, 41 respondents $(4.6$ percent of our sample) were not familiar with malaria. These households were dropped from the sample, leaving 569 respondents who were offered the hypothetical vaccine scenario and 279 respondents who were offered the bednet scenario. Approximately 114 interviews were completed for each of the five hypothetical vaccine prices and 56 for each of the five ITN prices (see Table 1).

\section{Characteristics of the Sample Population}

\section{Economic Characteristics}

The primary activity in Tembien is subsistence agriculture, with the main crops being sorghum, teff, maize, finger millet, wheat and legumes. Seventy percent of households reported their main occupation as farming; ninety percent of households said 
that they grow some crops. The combination of rainfed agriculture and unreliable rainfall (550-650 mm per year), however, results in low yields. The mean annual value of crop production for households that reported some agricultural output was Birr 658 (104 USD).

This was supplemented in most cases by income from livestock, especially cattle and goats. Livestock are also a form of investment. Oxen are the main energy source for cultivation and threshing, and donkeys are the main means by which produce is transported to local markets. In our sample, 55 percent of households owned at least one cow, 70 percent at least one ox and 34 percent at least one donkey. For households owning some livestock, the mean values of livestock holdings are presented in Table 2 .

Although there are few off-farm income earning opportunities, 55 percent of households who answered the question "What was the off-farm income of all members of this household last year?" reported positive earnings. Mean earnings, for households who reported positive earnings, were Birr 558 (89 USD).

To compute household income, we added the value of off-farm earnings, crop production and the annualized value of livestock holdings. Figure 1 presents the cumulative distribution of income for the sample. Mean household income is Birr 1,387 (220 USD) and median income is Birr 1,157 (183 USD). Figure 2 plots the percent of total income held by various fractions of the population (a Lorenz Curve); for example, the bottom 20 percent of families receive 4 percent of total income. The shape of this curve is consistent with Lorenz Curves for other developing countries.

\section{Family Composition and Education}

The average household in our sample consisted of two adults, two children and one teenager (see Table 3). Seventy-eight percent of households included both a husband and wife, while 20 percent were headed by single females. A typical household lived in a walled compound containing two single-room stone dwellings, one for sleeping and one for cooking. The mean respondent age was 42 , with men being slightly above the mean and women being slightly below it. Formal education is rare: three-quarters of our respondents had never been to school. Ten percent could read a newspaper with difficulty, while thirteen percent could easily read a newspaper. 


\section{Incidence of Malaria}

Malaria is endemic in Tembien. Transmission follows a seasonal pattern, with peak transmission occurring at the end of the rainy season (i.e., October through November), and, to a lesser extent, during the rainy season (i.e., June through September). Both Plasmodium falciparum and Plasmodium vivax are present, with Plasmodium falciparum predominating (Ghebreyesus, 1996). Government malaria control activities include spraying in outbreak areas, particularly in the early part of the peak transmission season; encouraging environmental control by communities, such as draining marshes and filling in ditches having standing water; and training volunteer community health workers to recognize and treat malaria with chloroquine.

Most respondents were very familiar with the disease. Sixty-eight percent named mosquitoes as one of the ways in which malaria is transmitted, and 98 percent identified fever or shivering, or a combination of the two, as symptoms of malaria. Seventy-six percent said that taking chloroquine is one of the best ways to cure someone who is sick with malaria. ${ }^{3}$ Most respondents ( 84 percent) drained areas near their home of standing water to prevent transmission of the disease.

Official statistics on malaria incidence in Tembien do not exist; however, data are available on the number of people receiving chloroquine from community health workers. Since community health workers treat malaria preemptively (microscopic facilities are found only at major health centers), these data measure malaria incidence with error. Despite this limitation, the seasonal pattern of malaria treatment fits the expected seasonal variation in malaria very well (Byass, 1995).

Table 4 summarizes self-reported malaria incidence in our sample. The disease is widespread, with 78 percent of respondents reporting that they have had the disease at least once in their lifetime. Incidence is fairly evenly distributed across household members. In the last two years, 58 percent of our respondents reported having had malaria at least once, 53 percent reported that at least one other adult in their household had malaria, and 49 percent reported that at least one teenager or child in their household had malaria. Seven percent of our sample said that someone in their family had ever died of malaria.

${ }^{3}$ Chloroquine, however, is rarely used as a form of prophylaxis. Only 7 percent of respondents took chloroquine to prevent malaria. 
Respondents who had the disease at least once in the last two years reported an average of 2.7 and a median of 2 episodes (or 1.3 and 1 per year). The average is skewed upward by 22 respondents who reported an unusually high number of episodes ( 7 or more) in the last two years. Such high responses could be accurate, but they might be attributed to a lack of understanding of the question or to the respondent confusing malaria with another febrile illness. If these observations are dropped from the sample, the average number of episodes falls to 0.9 per year, which is closer to the sample median of 1 episode per year. ${ }^{4}$ In addition to the respondent, on average 1.5 other adults and 2 children per household had the disease in the last two years.

At least two caveats are in order here. First, the malaria incidence in Table 4 is self-reported. It is well-known that self-diagnoses may confuse malaria with other febrile illnesses. To deal with this issue we report separate Cost of Illness information for the 131 respondents who said that their malaria was diagnosed with a medical test. ${ }^{5}$ Second, our recall period (two years) is an extremely long one. While respondents might reasonably be expected to recall whether or not they had malaria over this period, the details of a particular episode may be unreliable from the perspective of measuring Cost of Illness. ${ }^{6}$ To investigate this possibility we computed Cost of Illness estimates for malaria episodes that occurred between 2 and 4 months prior to the interview. Average Cost of Illness per episode, for adults and children, was 10 percent lower for the "short recall" sub-sample than for the sample as a whole.

\section{Cost of Illness Estimates}

Before turning to a formal model of household demand for vaccines or bednets, we present estimates of the costs of illness associated with the malaria episodes experienced by households in our sample. (The details of our computations appear in an appendix

\footnotetext{
${ }^{4}$ Inspection of the data reveals that these 22 respondents did not give unusual answers to the other survey questions about malaria. It would, therefore, appear that their responses may be the result of a lack of understanding of the specific question. For this reason, we did not drop these respondents from the sample.

${ }^{5}$ Respondents were asked if they had ever had malaria and, if so, how they knew this. We shall refer to respondents who said their malaria was diagnosed by a medical test as respondents whose malaria was ever diagnosed by a medical test, since we do not know if the test pertained to their most recent episode of malaria.

${ }^{6}$ We argue, however, that the respondent's recollection of his last episode is relevant to his decision to purchase vaccines. We therefore use self-reported Cost of Illness as a check on the validity of willingness to pay for vaccines.
} 
from the authors.) We use these estimates below to test the internal validity of willingness to pay responses.

In the medical economics literature the Cost of Illness (COI) is the sum of the costs of medical treatment (the "direct" costs of illness) and the value of productive time lost due to illness (the "indirect" costs of illness). Depending on the context, costs may be computed as either private costs or social costs. Private medical costs, for example, would include only the costs actually incurred by the sick person. These might fall short of social costs if, for example, the government subsidized the cost of medical care. In what follows, we compute the private costs of illness for the households in our sample.

We compute a per episode $\mathrm{COI}$ that reflects the costs of the most recent malaria episode experienced during the past two years for the respondent and a child/teenager in his household. We then multiply these costs by the number of episodes experienced by all family members during the last two years (and then divide by 2) to derive an annual household COI. These calculations are performed for all households in our sample, and for the sub-sample of households in which the respondent's malaria was ever confirmed by a medical test. ${ }^{7}$ As noted above, respondents whose malaria was ever confirmed by a medical test, report, on average, shorter episodes than our entire sample. ${ }^{8}$

Direct Costs of Illness

Our respondents reported that about 88 percent of malaria episodes were treated. Among treated cases of malaria, more than 89 percent were treated in a clinic or by a community health worker. Further, in about 60 percent of cases, respondents received chloroquine. ${ }^{9}$

The direct costs of illness (COI), shown in Table 5, are the out-of-pocket expenditures for seeing a health practitioner, for medicine, and for transportation to receive health care. All components of the direct $\mathrm{COI}$ are highest for adults. For the entire sample, the average direct COI for adults is Birr 10 (1.6 USD); for teens it is Birr 7 (1.1 USD), and for children it is Birr 5 (0.8 USD). Costs for each age category are higher

\footnotetext{
${ }^{7}$ In each case we have eliminated households whose duration of illness was greater than the ninety-fifth percentile of the sample distribution.

${ }^{8}$ Persons wishing to compare our estimates of the cost of illness with those from other studies may wish to focus on this sub-group.

${ }^{9}$ In 11 percent of cases respondents could not name the medication received. In 10 percent of cases, respondents received quinine, and in 1.4 percent of cases, fansidar.
} 
for households in which the respondent's malaria was ever clinically confirmed. ${ }^{10}$ These costs represent only the private costs of treatment and do not include the social costs of health care subsidies provided in many parts of Tigray. These subsidies include the free provision of both community health worker services and chloroquine.

\section{Indirect Cost of Illness}

The indirect costs of illness include the productive time lost by malaria patients, substitute laborers, and caretakers who did not perform their usual household activities. These time costs are the sum of three items. The first is the number of workdays that the malaria patient loses when ill. The second is the net time lost by a person who foregoes his own duties to substitute for the malaria patient at work. This time may be negative (i.e., it may reduce total time lost) if, for example, the substitute laborer gave up his leisure time. The third item is the workdays a caretaker missed while caring for the ill household member. ${ }^{11}$ The average number of workdays lost per malaria episode are shown in Table 6.

In 90 percent of malaria episodes, the respondent was unable to work. Intrahousehold labor substitution occurred in over two-thirds of these episodes. When substitution occurred, our findings indicate that, on average, it yielded a net gain in productivity. Over 70 percent of respondents' episodes, however, led to productivity losses from caretaking duties. This pattern is similar for the "medical test" sub-sample; however, the average number of workdays lost per episode is lower, for each age category, in this sub-group.

A measure of the monetary value of lost labor is needed to calculate the indirect COI in monetary terms. Most cost-of-illness studies assume that daily productivity is equal to the market wage rate, or some fraction thereof. This assumption is tenuous in Tigray, where labor markets are poorly developed, and farming is the primary occupation of most households. The absence of market wages plus the seasonal variability in the

\footnotetext{
${ }^{10}$ It should be noted that the sub-sample of households whose malaria was confirmed by a medical test is, on average, better educated than our entire sample.

11 We assume that all substitute labor and caretaking is intra-household. This is a reasonable assumption given that the basic farming unit is the household (REST, 1995).
} 
marginal productivity of on-farm labor makes it difficult to derive measures of daily productivity.

Since data are unavailable to estimate the daily productivity of agricultural workers, daily productivity is estimated by assuming that it is some fraction of the average daily wage for a healthy, unskilled worker. Our "high productivity" assumption equates adult productivity with the daily wage. Our "low productivity" assumption assumes productivity is half of the daily wage. Measuring lost productivity is further complicated by the fact that it is necessary to make assumptions about the productivity of teenagers and children relative to adults. We assume that a teenager's daily agricultural productivity is one-half of an adult's, and a child's daily productivity is one-quarter of an adult's. $^{12}$

\section{Total COI per Episode}

Table 7 summarizes total COI per episode for both productivity assumptions. Total COI per episode is lowest for children and almost equivalent for adults and teenagers.

On average, the COI per episode for the entire sample ranges from Birr 46 to 151 ( 7 to 24 USD) for adults, Birr 41 to 145 ( 7 to 23 USD) for teenagers, and Birr 23 to 78 ( 4 to 12 USD) for children. The upper range of these estimates is about $1 / 3$ lower for the subsample of households in which the respondent's malaria was ever clinically confirmed.

Annual household COI, based on all households, including those with no malaria episodes, is reported in Table 8. Average annual household COI ranges from Birr 196 (31 USD) using high productivity assumptions to Birr 58 (9 USD) using low productivity assumptions. Annual household COI averages Birr 103 (17 USD) if an adult's time is valued at 75 percent of the daily wage for unskilled labor.

\section{Household Demand for a Malaria Vaccine}

This section begins with a formal model of household demand for preventive medical care that is standard in the health economics literature (Grossman, 1972). The

\footnotetext{
12 In Tigray, adult men and women are responsible for most of the household activities, including grinding, food preparation, childcare, and agricultural activities. Teenagers assist in household activities, especially water fetching, fuel collection, livestock herding, and some agricultural activities. Children mainly herd livestock, collect fuel, and may assist with other agricultural activities if necessary (REST,1995).
} 
model is used to derive a demand function for a hypothetical malaria vaccine, which can be used to estimate a household's WTP for malaria prevention.

\section{A Model of the Demand for Health-Related Goods}

The traditional model of demand for health-related goods (Grossman, 1972) assumes that a household receives utility from consumption $(X)$ and leisure time $(L)$ and disutility from time spent ill $(S) .^{13}$ Using subscripts to represent the value of each variable to family member, $i=1, \ldots, n$, and assuming $n$ family members, household utility is given by

$$
U=u\left(X_{1}, \ldots, X_{n}, L_{1}, \ldots, L_{n}, S_{l}, \ldots, S_{n}, Z\right)
$$

The vector $Z$ represents taste variables that affect the weight the household places on the consumption of children v. adults, and on health v. other goods. $\mathbb{Z}$ might include the education level of the head of household, or the head's age and gender.

Time spent ill is, in turn, a function of the preventive care, $A_{i}$, and medical treatment, $M_{i}$, that each person receives. How effective these inputs are depends, of course, on individual characteristics, $H_{i}$. These would include baseline health and genetic predisposition to disease. In the case of malaria, time spent ill also depends on the prevalence of the vector (endemicity), $E$.

$$
S_{i}=s\left(A_{i}, M_{i}, H_{i}, E\right), \quad i=1, \ldots, n
$$

The amounts of preventive care, medical care and other goods that each person consumes are constrained by the household's budget. Specifically, total expenditure on these three goods cannot exceed the household's income,

$$
I+\sum_{i=1}^{n} w_{i}\left(T-L_{i}-S_{i}\right)=\sum_{i=1}^{n} X_{i}+p_{a} \sum_{i=1}^{n} A_{i}+p_{m} \sum_{i=1}^{n} M_{i}
$$

where $I$ is household non-earned income, the $w_{i}$ 's are the values of income (per unit time) generated by each family member, and $\sum w_{i}\left(T-L_{i}-S_{i}\right)$ is household earned income. ( $T$ is total time available.) The first term on the right-hand side of (3) is household expenditure on non-health goods, whose price is set equal to 1 . The second term

\footnotetext{
${ }^{13}$ We use bold uppercase letters to represent vectors.
} 
represents expenditures on preventive care, with price $p_{a}$. The last term represents expenditure on medical care, whose price is $p_{m}$.

The head of household selects values of $X, L, A$ and $\boldsymbol{M}$ to maximize household utility subject to the budget constraint and to the health production functions. This yields a household demand function for preventive care $A^{*}=\sum A_{i}$ that in general depends on non-wage income, wages, prices, household characteristics, health characteristics of family members, and the prevalence of malaria,

$$
A^{*}=\mathrm{g}\left(I, \mathbf{w}, p_{a}, p_{m}, \mathbf{Z}, \mathbf{H}, E\right)
$$

\section{Applicability of the Model to Northern Ethiopia}

To apply this model to the demand for malaria prevention in Ethiopia, we interpret $S_{i}$ as the amount of time person $\mathrm{i}$ is likely to spend ill with malaria over a year. While this is uncertain before the fact, we do not explicitly model the uncertainty associated with the disease. We argue that in cases where morbidity occurs regularly, such as diarrheal disease, acute respiratory infection, or seasonal malaria, it is appropriate to use a model of choice under certainty. ${ }^{14}$ Such a model would not be appropriate if morbidity were infrequent (e.g., a heart attack or stroke) or likely to result in death. Risk of death from malaria in Tigray is low, relative to risk of death from other causes. In Tigray, 8 persons out of every 10,000 die each year from malaria (Ethiopian Ministry of Health, 1996). This implies that, an on average, one person per year would be likely to die of malaria in one of our study villages. By contrast, risk of death from other causes is 16 per 1,000 people. $^{15}$

One difficulty in applying the traditional household production model to an agricultural economy lies in measuring the productivity of each household member $\left(w_{i}\right)$. If each family member worked outside the home, $w_{i}$ would be measured by the wage rate. If family members work on a family farm, one could replace the household's income by

\footnotetext{
${ }^{14}$ This is the standard practice in the profession. See, for example, Freeman (1993).

${ }^{15}$ Risk of death is, of course, higher among children than adults. We acknowledge that respondents may consider the possibility that their children may die of malaria, and that this may provide a motive for buying them a malaria vaccine.
} 
an agricultural production function, in which output depends on the time input of each family member. This does not really solve the problem, however, since we do not have data to estimate such a production function. The reality is that obtaining values of individuals' time is a difficult empirical task. Moreover, such values are likely to vary with the season of the year; in Tigray, a person's time is more valuable during planting and harvest seasons and less valuable at other times. In spite of these difficulties, we believe that this model captures important aspects of the demand for health in Tigray.

\section{Willingness to Pay for Malaria Prevention}

In our survey, the most complete form of preventive care offered to households was a hypothetical malaria vaccine. Households were told that the vaccine would prevent each person who received it from contracting malaria for one year. It is, therefore, the case that $S_{i}=0$ if the vaccine is purchased. How many vaccines a household would choose to buy depends, of course, on the price of the vaccine, and upon the household's income. The demand curve pictured in Figure 3 represents the number of vaccines a household would purchase as a function of price, holding income constant. The demand curve may also be interpreted as the household's marginal willingness to pay curve for additional vaccines. That is, the monetary value shown on the demand curve above each quantity is the most the household would pay for that unit of the good.

Because the hypothetical vaccine offers total protection against malaria, the value to a household of preventing malaria is the value it attaches to having $n$ vaccines (i.e., one for each family member), which would protect all members of the household from malaria for one year. The household's maximum willingness to pay for $n$ vaccines is the area under the household's demand (marginal willingness to pay) curve from 0 to $n$; i.e., the shaded area in Figure 3. We define this to be the value to a household of totally preventing malaria (WTP for total prevention) and, in Part III, calculate it for each household in our study. ${ }^{16}$

An interesting question is how WTP for total prevention compares with the Cost of Illness--the value of productivity losses and medical expenditures that the household would incur if it did not purchase the vaccine. In the notation of the model, the expected COI for the household over a year is

\footnotetext{
${ }^{16}$ We note that the demand curves for poor households may reach the $\mathrm{x}$-axis before $n$. For these households, WTP for prevention is the entire area under the demand curve.
} 


$$
\mathrm{COI}^{*}=\sum\left(w_{i} S_{i}+p_{m} M_{i}\right)
$$

where the values of $S_{i}$ and $M_{i}$ are calculated assuming that no vaccine is available. In Part III we compare COI with WTP for total prevention. 


\section{RESULTS}

\section{Empirical Analysis of Vaccine Demand}

\section{Description of Responses}

Figure 4 and Table 9 show the number of vaccines respondents stated that they would purchase at various prices. Quantity purchased is clearly sensitive to price. The percent of households who say that they would buy no vaccines increases from 24 percent at a price of Birr 5 (0.80 USD) to 90 percent at a price of Birr 200 (32 USD) per vaccine. The average quantity purchased also declines as price rises.

An important issue for policy is who within families would receive vaccines if they were available. Table 10 presents the percent of adults, teenagers and children who would receive the vaccine by income category. (The percentage of persons receiving the vaccine in each case represents an average across sample prices.) Two facts about the table are striking. The first is that the percent of adults, teenagers and children receiving the vaccine increases very slowly with income. The second is that the percentage of adults receiving the vaccine is, on average, higher than the percent of teenagers and children. This result, which is confirmed by our multivariate results below, suggests that productivity concerns may motivate the allocation of vaccines among family members.

The data underlying Tables 9 and 10 can also be used to predict the number of vaccines that would be purchased in a village of 200 households, assuming that these households have the same characteristics as those in our sample. Figure 5 plots the number of vaccines purchased at each of our sample prices, and connects these points. At a price of Birr 20 (3.2 USD) 400 persons ( 40 percent of the population of the village) would receive the vaccine. At a price of Birr 100 (16 USD), however, only 150 people would receive the vaccine. Since the revenue from selling 150 vaccines at Birr 100 per vaccine is almost twice as great as the revenue from selling 400 vaccines at Birr 20 per vaccine, there is clearly a trade-off between coverage and profit maximization, were a vaccine to be sold as a private good.

\section{Estimation of Household Demand Functions}

To see how quantity demanded varies parametrically with price and with covariates, we estimate several forms of the demand function. This also provides a test of 
the internal validity of our responses: quantity demanded should increase with income and education, holding other variables constant. The discrete nature of the data suggests using a count data model, such as the Poisson or Negative Binomial. Below, we present results for three models, the Poisson, the Negative Binomial, and the Truncated Poisson. The last model imposes on the Poisson model the constraint that a household will never purchase more than $n$ vaccines.

The model described in Part II suggests that the number of vaccines purchased should depend on vaccine price, household income and family size. It might also depend on family composition, i.e., on the number of adults, children and teenagers in the family, and on characteristics of the respondent--gender, age, marital status and education--which may influence his taste for health-related goods. We measure education by whether the respondent can read a newspaper. Income, which enters the demand function in log form, is made up of three components: annual gross crop income, the annualized value of livestock holdings and reported annual off-farm wages. Since 28 percent of observations on off-farm wages are missing, we replace missing values with zero and then include a "missing wage" dummy variable, equal to one if off-farm income is not reported.

The demand for the vaccine should also depend on the incidence of malaria in the area and on family members' susceptibilities to the disease. We proxy malaria incidence by village altitude. We proxy household susceptibility to malaria with a variable that measures past experience with the disease. Specifically, we sum the number of malaria episodes that members of the household experienced during the last two years, weighting each episode by the average age-specific cost of treatment. ${ }^{17}$ This is the household's direct COI.

Household size is measured by a series of dummy variables. For example, HHSIZE5 $=1$ if the household has five members and $=0$ otherwise. This is because the number of vaccines respondents say they will purchase does not increase linearly with household size. Finally, we add a series of dummy variables to capture interviewer effects.

${ }^{17}$ The weights are those reported in Table 5 , based on all households in the sample. 
Table 11 presents parameter estimates for each of the three models. ${ }^{18}$ The results for the hypothetical vaccine models are generally consistent with economic theory. The number of vaccines that the respondent agrees to purchase decreases with price, respondent age and altitude. Other things equal, older respondents might perceive themselves to be at lower risk of contracting malaria than younger respondents. Respondents at higher altitudes, whose families are less exposed to the vector, should have a lower demand for the vaccine. Demand increases with income, susceptibility to the disease and being married. The income elasticity of demand, 0.4 , suggests that the vaccine is NOT viewed as a luxury good, a result that is consistent with the literature on willingness to pay to avoid illness. ${ }^{19}$ Price elasticity of demand ranges from -0.08 at a price of Birr 5 (0.8 USD) to -0.64 at a price of Birr 40 (6.4 USD).

The results for gender and family composition deserve some discussion. The coefficients on Married and Female indicate that women who are single heads of household have significantly lower demands for vaccines than single male heads of household or married women. It is also the case that, holding household size constant, the demand for vaccines is lower the larger the number of children in the household. This result makes sense from an economic perspective, since children contribute less to the household economically than do adults. It is also consistent with respondents' statements as to who in the family would receive a malaria vaccine. The percent of children and teenagers who would receive the vaccine is lower than the percent of adults who receive the vaccine.

\section{Model Selection}

Parameter estimates for each of the three models, while similar, are not identical. This raises the question: Which of the three models in Table 11 is preferred? Table 12 provides additional evidence by which to judge the models. The log of the likelihood function suggests that the Poisson model is inferior to models 2 and 3 . Indeed, a likelihood ratio test rejects the null hypothesis that the data follow a Poisson distribution (Model 1).

\footnotetext{
${ }^{18}$ Coefficients of the household size dummy variables and the interviewer dummy variables are reported in Appendix II.

${ }^{19}$ The income elasticity of willingness to pay to avoid illness, a related, but different concept from elasticity of demand, is typically between 0.3 and 0.6 (Loehman and De, 1982; Alberini et al., 1997).
} 
The two remaining models, the Negative Binomial and the Truncated Poisson, both under-predict the percent of households buying no vaccines and over-predict the percent buying one or two. The Negative Binomial model, however, predicts that households buy more vaccines than family members in 6 percent of the cases, whereas the Truncated Poisson model (by construction) never makes this error. This, together with the fact that the Truncated Poisson model produces the largest number of statistically significant coefficients, suggests that it is the preferred model.

As an additional test of the reasonableness of our results, we use the Truncated Poisson model to predict the amount that each household would spend on vaccines, at each price. The mean and median values of this amount, expressed as a percent of household income, are shown in Figure 6. Regardless of price, mean household expenditure (expressed as a percent of income) is never more than 4 percent. Median. household expenditure on the vaccine (as a percent of income) is never greater than 1.5 percent.

\section{WTP to Pay for Prevention}

Table 13 shows the implications of each of the three models for household WTP for total prevention. Calculated as the area under the household's demand curve between 0 and $n$ vaccines, annual household WTP is, on average Birr 229 (36 USD) (using the Truncated Poisson model), with a median value of Birr 158 (25 USD). Figure 7 shows the distribution of WTP across households. In the next section, we compare WTP with the costs of illness.

\section{Comparison of Willingness to Pay and Cost of Illness}

In this section, we compare the private costs of illness for households in our sample with WTP for prevention. We begin by noting that there is a difference between the Cost of Illness, as the term is used in the medical literature, and the COI in equation (5) above. The traditional Cost of Illness does not value lost leisure time; moreover, it is an ex post concept. That is, it is computed by adding up actual expenditures and valuing actual time lost due to illness that has occurred in the past. COI* in equation (5) includes the value of lost leisure time. Furthermore, since the purchase of vaccines would prevent future illness, COI* should represent expected future illness costs. 
How much $\mathrm{COI}$ and $\mathrm{COI}^{*}$ differ in practice depends (1) on the value attached to leisure time and (2) on the way in which households form their expectations. If the value of leisure time is zero, and households assume that the future will be exactly like the past, then the two concepts are identical. In what follows we assume that households attach a value of zero to their children's leisure time. In the case of adults, the number of leisure days lost to malaria is sufficiently small that we treat all time lost due to illness as productive time lost. We do, however, consider two ways in which households might form their expectations about future illness costs. Method one is to assume that their family's future illness costs will equal the costs they actually incurred last year, i.e., that $\mathrm{COI}^{*}=\mathrm{COI}$, as calculated in Table 8 . Method two is to assume that families look beyond their own experience and calculate their chances of contracting malaria using the relative frequency of the disease in the population and using average illness costs (Table 14).

\section{Expected COI Based on Average Sample Experience}

Our second method of calculating the expected COI assumes that the chance that an adult contracts malaria over the coming year equals the relative frequency of malaria among adults in our sample. A similar assumption is made for teenagers and children. To compute the cost of an episode, we use the average per episode cost, as reported in Table 7, based on all households. The resulting average annual household COI must be the same as the actual average COI shown in Table 8; however, COI figures for individual families will differ under the two approaches.

Table 15 shows the ratio of WTP for malaria prevention to the COI, computed under the assumption that adult productivity equals 0.75 of the daily wage for unskilled labor. This ratio was computed for each household in the sample, using WTP estimates from each of the three models in Table 13. The ratios were then averaged over all households. The results are quite similar for each of the three models, suggesting that WTP for total prevention of malaria is about 3 times as great as the cost of illness. This result is quite similar to results obtained in industrialized countries when WTP to avoid illness is compared with the conventional COI (Berger et al., 1987). It also has important policy implications. In evaluating the benefits of donor programs to control malaria, the use of conventional COI figures, computed as in Part II, are likely to significantly understate the benefits of such programs. 


\section{Household Demand for Bednets}

Insecticide-treated bednets have helped to reduce the incidence of vector-borne illness, as well as all-cause child mortality in various parts of Africa (Binka et al., 1997). At the time of our study, however, impregnated bednets were essentially unknown to households in Tigray as a method of treating malaria. ${ }^{20}$ In the six villages in which we administered the bednet scenario, our goal was to acquaint households with the use of an insecticide-treated net and then to ask the respondent how many nets he would purchase for his family at the price offered.

Table 16 and Figure 8 show the number of bednets households said that they would purchase at each price. Quantity demanded is clearly sensitive to price: the percent of households who declined to purchase nets increases from 19 percent at a price of Birr 8 (1.3 USD) to 63 percent at a price of Birr 100 (16 USD). The percentage of families who said they would buy two or more nets also declines monotonically as price rises. A rise in price from Birr 8 to Birr 20 (3.2 USD) and from Birr 20 to Birr 40 (6.4 USD), however, increases the percentage of families purchasing one net. Families who would buy two nets at a lower price buy only one net as the price rises.

At each income level, the percentage of adults, teenagers and children covered by bednets is much higher than the percent of each age group receiving vaccines (see Table 16). This reflects, in part, the lower household cost of bednets, as well as fact that the number of persons using a single net is flexible. Unlike vaccines, however, there is no preference for allocating bednets to adults rather than to children. Averaging across sample prices, 53 percent of adults and teenagers and 61 percent of children would sleep under bednets.

One reason for analyzing bednet demand is to predict the number of households who would purchase bednets at various prices. For example, Table 16 can be used to predict the fraction of households who would buy a bednet at a price that would permit cost recovery. It can also be used to determine what price would induce a desired fraction of households to purchase nets. Figure 9 illustrates the number of bednets that would be purchased in a village of 200 households, assuming that these households have 20 In response to the question "What are the best ways to avoid getting malaria?" only 4 respondents
mentioned sleeping under a bednet (either unimpregnated or impregnated). 
the same characteristics as those in our sample. At a price of Birr 40 (6.4 USD) per net, for example, 166 nets would be purchased. Calculating the number of people in the village who would be covered at this price requires an assumption about the number of people who sleep under a net. If this is two, then one-third of the population of the village would sleep under insecticide-treated nets at a price of Birr 40 (6.4 USD) per net.

Estimation of Household Demand Functions for Bednets

To estimate household demand functions for bednets we used models similar to those used for the hypothetical vaccine. In terms of the theoretical model of Part II, bednets are similar to vaccines. Both goods can prevent illness, although they do so in different ways. Bednets do not offer complete protection against malaria; however, they can reduce the inconvenience of insect bites, and can protect against other vector-borne diseases. We would therefore expect the number of bednets purchased to depend on the same factors as influence the demand for the hypothetical vaccine. Count data models are also appropriate in this case since households buy a non-negative integer quantity of bednets.

Table 17 presents estimates of Poisson, Negative Binomial and Truncated Poisson models of the demand for bednets. The explanatory variables are identical to those in the vaccine models. Fewer explanatory variables are, however, significant in the case of bednets. Indeed, the only variables whose coefficients are significantly different from zero are price, income and age of the respondent. Price is strongly significant in all three models, with a coefficient that is similar in magnitude to the coefficient of price in the vaccine models. Income is marginally significant in the Poisson and Negative Binomial models, as is respondent age. The income elasticity of demand for bednets is, however, much lower than for vaccines: a 10 percent increase in income increases the demand for bednets by only 1 percent. As in the case of vaccine, older respondents have lower demand than younger respondents do. ${ }^{21}$

The lack of significance of so many explanatory variables in the bednet models is due in part to the smaller sample of households receiving the bednet scenario (279 households) $v$, the vaccine scenario (569 households). We felt it more important to

${ }^{21}$ The lack of significance of the children and teenager variables mirrors respondents' answers to a question asking who would use the bednets. The percent of children who would receive bednets is not 
characterize the value of preventing malaria altogether, and therefore partitioned our sample to ensure accurate estimates of vaccine demand. Nevertheless, we believe Table 17 indicates that we probably have accurate estimates of the impact of price on the purchase of bednets, which is most likely the variable of greatest policy significance.

Table 18 compares the performance of the three models in predicting withinsample behavior. A likelihood ratio test fails to reject the null hypothesis that the data follow a Poisson distribution. Since the Poisson model is a special case of the Negative Binomial model and the Truncated Poisson model, it is not surprising that the three models produce similar results. All models over-predict the number of households purchasing zero bednets or one bednet and underpredict the number of households purchasing two or more bednets. This suggests that, for purposes of predicting bednet purchases, it is better to rely on the raw data in Table 16.

\section{Willingness to Pay for Bednets}

Our estimates of bednet demand can also be used, as above, to compute the household's total willingness to pay for a given number of nets. To illustrate, suppose that a donor were to provide enough bednets to protect all persons in a village. What are the economic benefits of such a program? The value to a household of owning $x$ nets (its total WTP for the nets) is the area under its demand curve between 0 and $x$ nets. Thus, the value of the program would be the sum of each household's total WTP for the nets it received. Assuming that each household received $n / 2$ nets, mean and median household WTP for bednets are given Table $19 .{ }^{22}$

The numbers in Table 19 are considerably lower than those in Table 13. Although bednets are a durable good, they provide only partial protection against malaria. Moreover, they require some effort to use. This helps to explain the fact that (using the preferred model in each case) median WTP for bednets is 72 percent of median WTP for vaccines. On the other hand, a bednet would probably provide protection against infection for 3 to 4 years if the insecticide were reapplied periodically, while the hypothetical vaccine was assumed to last for only one year.

significantly different from the percent of adults who would receive bednets.

22 When not an integer, $n / 2$ was rounded down to the nearest integer. 


\section{CONCLUSIONS}

The purpose of this report is to estimate the value households place on preventing malaria in Tigray, Ethiopia. Using the area under the household's demand function for vaccines to estimate this value, we find it to be about 36 USD per household per yearabout 15 percent of imputed annual household income. This is, on average, about two to three times the expected annual economic losses (medical costs plus productivity losses) per household from the disease.

Two points about this result deserve emphasis. First, it represents the private value to households of eliminating the disease. This is likely to be smaller than the social value of preventing malaria, which includes the costs of medical subsidies, community spraying and other government-sponsored programs. Second, this number represents the household's maximum willingness to pay for prevention. It is NOT the amount that would be obtained by selling malaria vaccines to all members of the family, unless the vaccines were sold by a price-discriminating monopolist. This latter point has important implications for cost recovery of malaria prevention schemes.

If a malaria vaccine were available, and if people in Tigray behaved as they told us they would in this survey, revenues from the sale of vaccines would be maximized at a price of 10 USD per vaccine. At this price, however, 75 percent of households would purchase no vaccines. This implies a steep trade-off between profit-maximization and population coverage. Our bednet results carry similar implications. Figure 8 suggests that, at a price that might permit cost recovery (6 USD per bednet), only one-third of the population of a 200 -person village would sleep under bednets.

What causes this apparent contradiction in results is the shape of the demand curves for bednets and vaccines. Both are very steep-implying that, as the price of each good falls, the number purchased increases, but gradually. This makes it possible for households' WTP for $\mathrm{n}$ vaccines to be large (15 percent of income) even though the percent of income spent on vaccines, which reflects the number actually purchased, is small (never more than 4 percent of income). The policy implications of this result are that, while the benefits from allocating resources to bednets or malaria vaccines are large, 
it will be difficult for either good to achieve significant market penetration unless the price is subsidized. 


\section{REFERENCES}

Alberini, A., M. Cropper, T, Fu, A. Krupnick, J. Liu, D. Shaw and W. Harrington (1997), "Valuing Health Effects of Air Pollution in Developing Countries: The Case of Taiwan," Journal of Environmental Economics and Management, 34, 107-126.

Berger, M., G. Blomquist, D. Kenkel, and G. Tolley. 1987. Valuing Changes in Health Risks: A Comparison of Alternative Measures. Southern-Economic-Journal; 53(4), 967-84.

Binka, F., O. Nensah, and A. Mills. 1997. The Cost Effectiveness of Ermethrin Impregnated Bednets in Preventing Child Mortality in Kassena-Nankana District of Northern Ghana. Health Policy; 41, 229-239.

Byass, P. 1995. Written communication to Melba Gomes, WHO.

Ethiopia Ministry of Health. 1996. Burden of Disease. Ethiopia Social Sector Study Report. September.

Freeman. M., 1993. The Measurement of Environmental and Resource Values: Theory and Practice. Resources for the Future: Washington, D.C.

Ghebreyesus, T., T. Alemayehu, A. Bosman, K. Witten, and A. Teklehaimanot. 1996. Community Participation in Malaria Control in Tigray region Ethiopia. Acta Tropica; 61, 145-156.

Gomes, M. 1993. Economic and Demographic Research on Malaria: A Review of the Evidence. Social Science and Medicine; 37, 1093-1108.

Grossman, M. 1972. On the Concept of Health Capital and the Demand for Health. Journal of Political Economy; 80(2), 223-55

Hammer, J. 1993. The Economics of Malaria Control. The World Bank Research Observer; 8, 1-22.

Loehman, E., and V. De (1982), "Application of Stochastic Choice Modeling to Policy Analysis of Public Goods: A Case Study of Air Quality Improvements," The Review of Economics and Statistics, 64(3), 474-480.

REST (Relief Society of Tigray). 1995. Farming Systems, Resource Management and Household Coping Strategies in Northern Ethiopia: Report of a Social and AgroEcological Baseline Study in Central Tigray. 
Whittington, D., A. Pinheiro. and M. Cropper. 1996. The Economic Benefits of Malaria Control: A Contingent Valuation Study in Marracuene, Mozambique. Unpublished Manuscript. 
Table 1. Number of Households Receiving Each Version of Questionnaire ( $\mathrm{n}$; column percent)

\begin{tabular}{|c|c|c|c|}
\hline \multicolumn{2}{|c|}{ Hypothetical Vaccine Scenario } & \multicolumn{2}{|c|}{ Bednet Scenario } \\
\hline Price (Birr) & Sample Size & Price (Birr) & Sample Size \\
\hline 5 & $117(21 \%)$ & 8 & $58(21 \%)$ \\
\hline 20 & $120(21 \%)$ & 20 & $59(21 \%)$ \\
\hline 40 & $117(21 \%)$ & 40 & $54(19 \%)$ \\
\hline 100 & $118(21 \%)$ & 60 & $52(19 \%)$ \\
\hline 200 & $97(17 \%)$ & 100 & $56(20 \%)$ \\
\hline Total & $569(100 \%)$ & Total & $279(100 \%)$ \\
\hline
\end{tabular}

Table 2. Mean Value of Livestock for Households Who Own Livestock (Birr*)

\begin{tabular}{lcccc}
\hline Type of Livestock & N & Mean & Price & Value \\
\hline Sheep & 219 & 5 & 80 & 402 \\
Oxen & 594 & 2 & 875 & 1632 \\
Goats & 395 & 7 & 60 & 437 \\
Chickens & 674 & 6 & 7 & 41 \\
Cattle & 475 & 2 & 200 & 495 \\
Donkey & 291 & 1 & 300 & 412 \\
\hline
\end{tabular}

$* 1$ USD $=$ Birr 6.3 
Table 3. Household Demographic Characteristics

\begin{tabular}{lccc}
\hline Variable & Obs & Mean & Median \\
\hline Household size & 848 & 5 & 5 \\
Number of adults & 848 & 2 & 2 \\
Number of teenagers & 848 & 1 & 0 \\
Number of children & 848 & 2 & 2 \\
Respondent gender (0=male \& 1=female) & 848 & $57 \%$ & 1 \\
Respondent age & 847 & 42 & 40 \\
Respondent can read newspaper easily & 848 & $13 \%$ & 0 \\
\hline
\end{tabular}

Table 4. Household Malaria Incidence (in last 2 years unless otherwise specified)

\begin{tabular}{lccc}
\hline Variable & $\mathrm{N}$ & $\begin{array}{c}\text { Mean } \\
\text { [Trimmed } \\
\text { Mean] }\end{array}$ & Median \\
\hline Respondent had malaria in lifetime & 848 & $78 \%$ & 1 \\
Respondent had malaria & 848 & $58 \%$ & 1 \\
Households where other adults had malaria & 842 & $53 \%$ & 1 \\
Households where children/teens had malaria & 845 & $49 \%$ & 0 \\
Households where somebody died of malaria & 803 & $7 \%$ & 0 \\
(lifetime) & 656 & $2.7[1.8]$ & 2 \\
No. times the respondent had malaria & 451 & 1.5 & 1 \\
No. of other adults who have had malaria & 415 & 2.0 & 2 \\
No. children/teenagers who have had malaria & & &
\end{tabular}

*Trimmed means are obtained by setting all values greater than the ninety-fifth percentile equal to the ninety-fifth percentile. 
Table 5. Elements of Direct Cost of Illness per Episode, Sample Averages by Age Group

\begin{tabular}{|l|c|c|c|c|}
\hline Variable & \multicolumn{2}{|c|}{ All Households } & \multicolumn{2}{c|}{$\begin{array}{c}\text { Households Who Ever Had Malaria } \\
\text { Confirmed by a Medical Test }\end{array}$} \\
\hline Adults & Birr & USD & Birr & USD \\
\hline Treatment Costs & 8 & 1.3 & 10 & 1.6 \\
\hline Costs of Medicine & $1.4^{23}$ & 0.2 & $1.6^{24}$ & 0.3 \\
\hline $\begin{array}{l}\text { Transportation } \\
\text { Costs }\end{array}$ & $0.6^{25,26}$ & 0.1 & $0.8^{27}$ & 0.1 \\
\hline Direct COI & 10 & 1.6 & 13 & 2.0 \\
\hline Teenagers & & & & 10 \\
\hline Treatment Costs & 5 & 0.8 & 10 & 1.5 \\
\hline Costs of Medicine & $1.4^{28}$ & 0.2 & $1^{29}$ & 0.2 \\
\hline $\begin{array}{l}\text { Transportation } \\
\text { Costs }\end{array}$ & $0.2^{30,31}$ & 0.04 & $0.8^{32}$ & 0.1 \\
\hline Direct COI & 7 & 1.1 & 11 & 1.8 \\
\hline Children & & & & 0.8 \\
\hline Treatment Costs & 4 & 0.6 & 5 & 0.2 \\
\hline Costs of Medicine & 1.033 & 0.2 & $1.1^{34}$ & 0.05 \\
\hline $\begin{array}{l}\text { Transportation } \\
\text { Costs }\end{array}$ & $0.1^{35,36}$ & 0.02 & $0.3^{37}$ & 1.0 \\
\hline Direct COI & 5 & 0.8 & 7 & \\
\hline
\end{tabular}

* Rounding errors account for direct COI estimates that are not sums of its three components.

${ }^{23}$ The average of cost of medicine for those that paid is Birr 7 .

${ }^{24}$ The average of cost of medicine for those that paid is Birr 5 .

${ }^{25}$ Values that are greater than the ninety-fifth percentile are replaced with the value of the ninetyfifth percentile (Birr 10).

${ }^{26}$ The average transportation costs over only households that incurred travel costs are Birr 7.

${ }^{27}$ The average transportation costs over only households that incurred travel costs are Birr 6 .

${ }^{28}$ The average of cost of medicine for those that paid is Birr 7.

${ }^{29}$ The average of cost of medicine for those that paid is Birr 8 .

${ }^{30}$ Values that are greater than the ninety-fifth percentile are replaced with the value of the ninetyfifth percentile (Birr 6).

${ }^{31}$ The average transportation costs over only households that incurred travel costs are Birr 5.

${ }^{32}$ The average transportation costs over only households that incurred travel costs are Birr 6.

${ }^{33}$ The average of cost of medicine for those that paid is Birr 7.

${ }^{34}$ The average of cost of medicine for those that paid is Birr 6 .

${ }^{35}$ Values that are greater than the ninety-fifth percentile are replaced with the value of the ninetyfifth percentile (Birr 6).

${ }^{36}$ The average transportation costs over only households that incurred travel costs are Birr 5.

${ }^{37}$ The average transportation costs over only households that incurred travel costs are Birr 4. 
Table 6. Productivity Losses Per Malaria Episode, by Age Group (Average Number of Days)

\begin{tabular}{l|c|c|c|c|c|c}
\hline & \multicolumn{3}{|c|}{ All Households } & \multicolumn{3}{c}{$\begin{array}{c}\text { Households Who Ever } \\
\text { Had Malaria Confirmed } \\
\text { by a Medical Test }\end{array}$} \\
\hline & Adult & Teens & Children & Adult & Teens & Children \\
\hline Duration of Illness & 22 & 26 & 16 & 19 & 28 & 11 \\
\hline Patient's Lost Work Days & 18 & 18 & 2 & 14 & 19 & 2 \\
\hline $\begin{array}{l}\text { Gains in Household } \\
\text { Productivity Due to Intra- } \\
\text { household Labor Substitution }\end{array}$ & 14 & 10 & 1 & 12 & 10 & 1 \\
\hline $\begin{array}{l}\text { Losses in Household } \\
\text { Productivity Because } \\
\text { Substitute Laborer Does Not } \\
\text { Do Their Own Work }\end{array}$ & 6 & 5 & 1 & 3 & 2 & 1 \\
\hline $\begin{array}{l}\text { Days Lost Due To Intra- } \\
\text { household Caretaking }\end{array}$ & 11 & 13 & 11 & 9 & 6 & 7 \\
\hline $\begin{array}{l}\text { Net Number of Work Days } \\
\text { Lost Due to an Episode of } \\
\text { Malaria }\end{array}$ & 21 & 26 & $12^{*}$ & $15^{*}$ & 17 & $8^{*}$ \\
\hline
\end{tabular}

*These columns do not add up because of rounding errors.

Table 7. Average Cost of Illness Per Episode, Using High and Low Productivity Assumptions

\begin{tabular}{|l|c|c|c|c|}
\hline $\begin{array}{l}\text { Age } \\
\text { Group }\end{array}$ & \multicolumn{2}{|c|}{ All Households } & \multicolumn{2}{c|}{$\begin{array}{l}\text { Households Who Ever Had } \\
\text { Malaria Confirmed by a Medical } \\
\text { Test }\end{array}$} \\
\hline & 1997 Birr & 1997 USD & 1997 Birr & 1997 USD \\
\hline Adults & $46-151$ & $7-24$ & $38-113$ & $6-18$ \\
\hline Teenagers & $41-145$ & $7-23$ & $32-94$ & $5-15$ \\
\hline Children & $23-78$ & $4-12$ & $19-55$ & $3-9$ \\
\hline
\end{tabular}


Table 8. Average Annual Cost of Illness Per Household, Using Actual Illness ( $\mathrm{n}=848$ )

\begin{tabular}{|c|c|c|}
\hline $\begin{array}{c}\text { Daily Productivity } \\
\text { (Percent of Daily } \\
\text { Wage) }\end{array}$ & $\begin{array}{c}\text { 1997 Birr } \\
\text { Mean [std. dev.] }\end{array}$ & $\begin{array}{c}\text { 1997 USD } \\
\text { Mean [std. dev.] }\end{array}$ \\
\hline 100 & $196[150]$ & $31[24]$ \\
\hline 75 & $103[80]$ & $16[13]$ \\
\hline 50 & $58[45]$ & $9[7]$ \\
\hline
\end{tabular}

Table 9. Number of Hypothetical Vaccines Purchased by Price

\begin{tabular}{lcccc}
\hline & 0 vaccines & $1-3$ vaccines & $4-6$ vaccines & $>=7$ vaccines \\
\hline Price 5 & $24 \%$ & $35 \%$ & $33 \%$ & $8 \%$ \\
Price 20 & $48 \%$ & $25 \%$ & $22 \%$ & $6 \%$ \\
Price 40 & $68 \%$ & $21 \%$ & $10 \%$ & $2 \%$ \\
Price 100 & $81 \%$ & $10 \%$ & $6 \%$ & $3 \%$ \\
Price 200 & $90 \%$ & $6 \%$ & $4 \%$ & $0 \%$ \\
\hline
\end{tabular}

Table 10. Coverage with Vaccines by Income Group and Demographic Category

\begin{tabular}{cccc}
\hline Annual Income & Adults & Teenagers & Children \\
\hline Low $(<$ Birr 800$)$ & $27 \%$ & $21 \%$ & $23 \%$ \\
$N$ & 409 & 131 & 322 \\
Middle & $28 \%$ & $25 \%$ & $31 \%$ \\
$N$ & 448 & 141 & 395 \\
High $(>$ Birr 1,550) & $29 \%$ & $31 \%$ & $24 \%$ \\
$N$ & 470 & 187 & 394 \\
\hline
\end{tabular}


Table 11. Parameter Estimates for Hypothetical Vaccine Models $(n=569)$

\begin{tabular}{|c|c|c|c|}
\hline Variable & Poisson & $\begin{array}{l}\text { Negative } \\
\text { Binomial }\end{array}$ & $\begin{array}{l}\text { Truncated } \\
\text { Poisson }\end{array}$ \\
\hline Price & $-0.012^{* *}$ & $-0.014^{* *}$ & $-0.016^{* *}$ \\
\hline (Birr) & 0.001 & 0.001 & 0.001 \\
\hline Log household income & $0.209^{* *}$ & $0.288^{* *}$ & $0.402^{* *}$ \\
\hline (thousands of Birr) & 0.056 & 0.108 & 0.052 \\
\hline Missing wage & -0.002 & -0.014 & 0.059 \\
\hline ( 1 if no wage) & 0.122 & 0.211 & 0.106 \\
\hline Number of teenagers & 0.023 & -0.033 & 0.001 \\
\hline (number) & 0.067 & 0.133 & 0.058 \\
\hline Number of children & $-0.098^{*}$ & $-0.206^{*}$ & $-0.222^{* *}$ \\
\hline (number) & 0.058 & 0.112 & 0.047 \\
\hline Household dir. cost of illness & $0.011^{* *}$ & $0.013^{* *}$ & $0.016^{* *}$ \\
\hline (Birr) & 0.003 & 0.005 & 0.002 \\
\hline Married & $0.297^{* *}$ & 0.402 & $0.475^{* *}$ \\
\hline (1 if Married) & 0.140 & 0.261 & 0.135 \\
\hline Gender & $-0.150^{*}$ & $-0.265^{*}$ & $-0.281^{* *}$ \\
\hline ( 1 if female) & 0.083 & 0.159 & 0.072 \\
\hline Read & $0.196^{* *}$ & $0.313^{*}$ & $0.291^{* *}$ \\
\hline ( 1 if read easily) & 0.086 & 0.167 & 0.072 \\
\hline Age & $-0.011^{* *}$ & $-0.016^{* *}$ & $-0.021^{* *}$ \\
\hline (years) & 0.003 & 0.006 & 0.003 \\
\hline $\begin{array}{l}\text { Altitude } \\
\text { (hundreds of meters) }\end{array}$ & $\begin{array}{c}-0.062^{* *} \\
0.026\end{array}$ & $\begin{array}{c}-0.085^{*} \\
0.047\end{array}$ & $\begin{array}{c}-0.082^{* *} \\
0.021\end{array}$ \\
\hline Intercept & $\begin{array}{l}0.590 \\
0.610\end{array}$ & $\begin{array}{l}0.839 \\
1.071\end{array}$ & $\begin{array}{c}2.137^{* *} \\
0.725\end{array}$ \\
\hline $\operatorname{Ln} \alpha$ & & $\begin{array}{c}0.058 \\
0.148\end{array}$ & \\
\hline
\end{tabular}

Notes: Dichotomous variables for household size and enumerators are not included in Table. Standard errors in small font.

** Significant at the $5 \%$ level

${ }^{*}$ Significant at the $10 \%$ level 
Table 12. Goodness of Fit Criteria for Hypothetical Vaccine Model

\begin{tabular}{lcccc}
\hline & Actual & Poisson & $\begin{array}{c}\text { Negative } \\
\text { Binomial }\end{array}$ & $\begin{array}{c}\text { Truncated } \\
\text { Poisson }\end{array}$ \\
\hline Log Likelihood & N/A & -856.26 & -764.05 & -768.71 \\
Mean Y|X & 1.45 & 1.45 & 1.63 & 1.06 \\
Variance of Y|X & 4.74 & 2.34 & 5.28 & 1.05 \\
Y > household size & $0 \%$ & $2 \%$ & $6 \%$ & $0 \%$ \\
Frequency & & & & \\
0 & $61 \%$ & $52 \%$ & $56 \%$ & $59 \%$ \\
1 & $6 \%$ & $23 \%$ & $19 \%$ & $24 \%$ \\
2 & $7 \%$ & $12 \%$ & $9 \%$ & $10 \%$ \\
3 & $7 \%$ & $5 \%$ & $5 \%$ & $6 \%$ \\
4 & $7 \%$ & $6 \%$ & $3 \%$ & $1 \%$ \\
5 & $6 \%$ & $2 \%$ & $2 \%$ & $0 \%$ \\
6 or more & $7 \%$ & $2 \%$ & $6 \%$ & $0 \%$ \\
\hline
\end{tabular}

Table 13. Willingness to Pay for Hypothetical Vaccine $(n=569)$

\begin{tabular}{lccc}
\hline & Poisson & $\begin{array}{c}\text { Negative } \\
\text { Binomial }\end{array}$ & $\begin{array}{c}\text { Truncated } \\
\text { Poisson }\end{array}$ \\
\hline Willingness to pay & 202 & 205 & 229 \\
Mean & 163 & 139 & 158 \\
Median & 147 & 188 & 208 \\
Standard Deviation & 7 & 6 & 7 \\
Minimum & 883 & 1046 & 1117 \\
Maximum & & \\
\hline
\end{tabular}

Table 14. Average Annual Cost of Illness Per Household Using Sample Illness

Frequencies to Predict Future Illness and Average Per Episode COI (Entire Sample)

\begin{tabular}{|c|c|c|}
\hline $\begin{array}{l}\text { Daily Productivity } \\
\text { (Percent of Daily } \\
\text { Wage) }\end{array}$ & $\begin{array}{c}1997 \text { Birr } \\
\text { Mean [std. dev.] }\end{array}$ & $\begin{array}{c}1997 \text { USD } \\
\text { Mean [std.dev.] }\end{array}$ \\
\hline 100 & $196[183]$ & $31[29]$ \\
\hline 75 & $104[97]$ & $17[15]$ \\
\hline 50 & $59[55]$ & $9[9]$ \\
\hline
\end{tabular}


Table 15. Ratios of Three Estimates of WTP for Malaria Vaccine to Two estimates of Expected Cost of Illness Per Household

\begin{tabular}{|l|c|c|}
\hline $\begin{array}{l}\text { Models Used to } \\
\text { Estimate WTP }\end{array}$ & $\begin{array}{c}\text { Mean of Ratio of WTP to } \\
\text { Actual Household COI (See } \\
\text { Table 8) [std. dev.] }\end{array}$ & $\begin{array}{c}\text { Mean of Ratio of WTP to Ex } \\
\text { Ante Household COI (See } \\
\text { Table 14) [std. dev.] }\end{array}$ \\
\hline Truncated Poisson & $3.10[4.03]$ & $2.32[1.98]$ \\
\hline Poisson & $2.80[3.33]$ & $1.98[1.37]$ \\
\hline Negative Binomial & $2.76[3.58]$ & $2.01[1.71]$ \\
\hline
\end{tabular}

Table 16. Number of Bednets Purchased by Price

\begin{tabular}{lcccc}
\hline & 0 nets & 1 net & 2 nets & 3 or more nets \\
\hline Price 8 & $19 \%$ & $21 \%$ & $43 \%$ & $17 \%$ \\
Price 20 & $22 \%$ & $33 \%$ & $32 \%$ & $13 \%$ \\
Price 40 & $41 \%$ & $37 \%$ & $20 \%$ & $2 \%$ \\
Price 60 & $52 \%$ & $23 \%$ & $19 \%$ & $6 \%$ \\
Price 100 & $63 \%$ & $25 \%$ & $11 \%$ & $2 \%$ \\
\hline
\end{tabular}


Table 17. Parameter Estimates for Bednet Models $(n=279)$

\begin{tabular}{|c|c|c|c|}
\hline Variable & Poisson & $\begin{array}{l}\text { Negative } \\
\text { Binomial }\end{array}$ & $\begin{array}{c}\text { Truncated } \\
\text { Poisson }\end{array}$ \\
\hline Price & $-0.014^{* *}$ & $-0.014^{* *}$ & $-0.016^{* \pi}$ \\
\hline (Birr) & 0.002 & 0.002 & 0.003 \\
\hline Log household income & $0.093^{*}$ & $0.093^{*}$ & 0.097 \\
\hline (thousands of Birr) & 0.059 & 0.059 & 0.075 \\
\hline Missing wage & 0.019 & 0.019 & 0.265 \\
\hline (1 if no wage) & 0.188 & 0.188 & -0.132 \\
\hline Number of teenagers & 0.116 & 0.117 & .0 .118 \\
\hline (number) & 0.109 & 0.109 & 0.147 \\
\hline Number of children & 0.044 & 0.044 & 0.032 \\
\hline (number) & 0.099 & 0.099 & 0.142 \\
\hline Household dir. cost of illness & -0.005 & -0.005 & -0.006 \\
\hline (Birr) & 0.005 & 0.005 & 0.006 \\
\hline Married & .0 .045 & 0.045 & 0.022 \\
\hline ( 1 if married) & 0.195 & 0.195 & 0.271 \\
\hline Gender & 0.012 & 0.012 & 0.009 \\
\hline ( 1 if female) & 0.146 & 0.146 & 0.213 \\
\hline Read & 0.022 & 0.022 & -0.010 \\
\hline ( 1 if read easily) & 0.160 & 0.160 & 0.224 \\
\hline Age & $-0.010^{* *}$ & $-0.010^{* *}$ & -0.012 \\
\hline (years) & 0.005 & 0.005 & 0.008 \\
\hline Altitude & 0.067 & 0.067 & 0.082 \\
\hline (hundreds of meters) & 0.038 & 0.038 & 0.049 \\
\hline Intercept & $\begin{array}{c}-0.541 \\
0.844\end{array}$ & $\begin{array}{c}-0.541 \\
0.846\end{array}$ & $\begin{array}{c}0.461 \\
1.116\end{array}$ \\
\hline $\operatorname{Ln} \alpha$ & & -17.323 & \\
\hline
\end{tabular}

Notes: Dichotomous variables for household size and enumerators are not included in Table. Standard errors in small font.

** Significant at the $5 \%$ level

* Significant at the $10 \%$ level 
Table 18. Goodness of Fit Criteria for Bednets

\begin{tabular}{lcccc}
\hline & Actual & Poisson & $\begin{array}{c}\text { Negative } \\
\text { Binomial }\end{array}$ & $\begin{array}{c}\text { Truncated } \\
\text { Poisson }\end{array}$ \\
\hline Log Likelihood & N/A & -322.30 & -322.30 & -311.75 \\
Mean Y|X & 1.07 & 1.07 & 1.07 & 1.09 \\
Variance of Y|X & 1.63 & 0.56 & 0.56 & 0.57 \\
Y>(household size) $/ 2$ & $0 \%$ & $2 \%$ & $2 \%$ & $0 \%$ \\
Frequency & & & & \\
0 & $39 \%$ & $54 \%$ & $54 \%$ & $52 \%$ \\
1 & $28 \%$ & $37 \%$ & $37 \%$ & $38 \%$ \\
2 & $25 \%$ & $8 \%$ & $8 \%$ & $8 \%$ \\
3 & $6 \%$ & $1 \%$ & $1 \%$ & $1 \%$ \\
4 & $0 \%$ & $0 \%$ & $0 \%$ & $0 \%$ \\
5 & $0 \%$ & $0 \%$ & $0 \%$ & $0 \%$ \\
6 or more & $1 \%$ & $0 \%$ & $0 \%$ & $0 \%$ \\
\hline
\end{tabular}

Table 19. Willingness to Pay for Bednets $(n=279)$

\begin{tabular}{lccc}
\hline & Poisson & $\begin{array}{c}\text { Negative } \\
\text { Binomial }\end{array}$ & $\begin{array}{c}\text { Truncated } \\
\text { Poisson }\end{array}$ \\
\hline Willingness to pay & 123 & 123 & 138 \\
Mean & 113 & 113 & 122 \\
Median & 68 & 68 & 84 \\
Standard Deviation & 18 & 18 & 6 \\
Minimum & 465 & 465 & 597 \\
Maximum & & \\
\hline
\end{tabular}


Figure 1. Cumulative Income Distribution

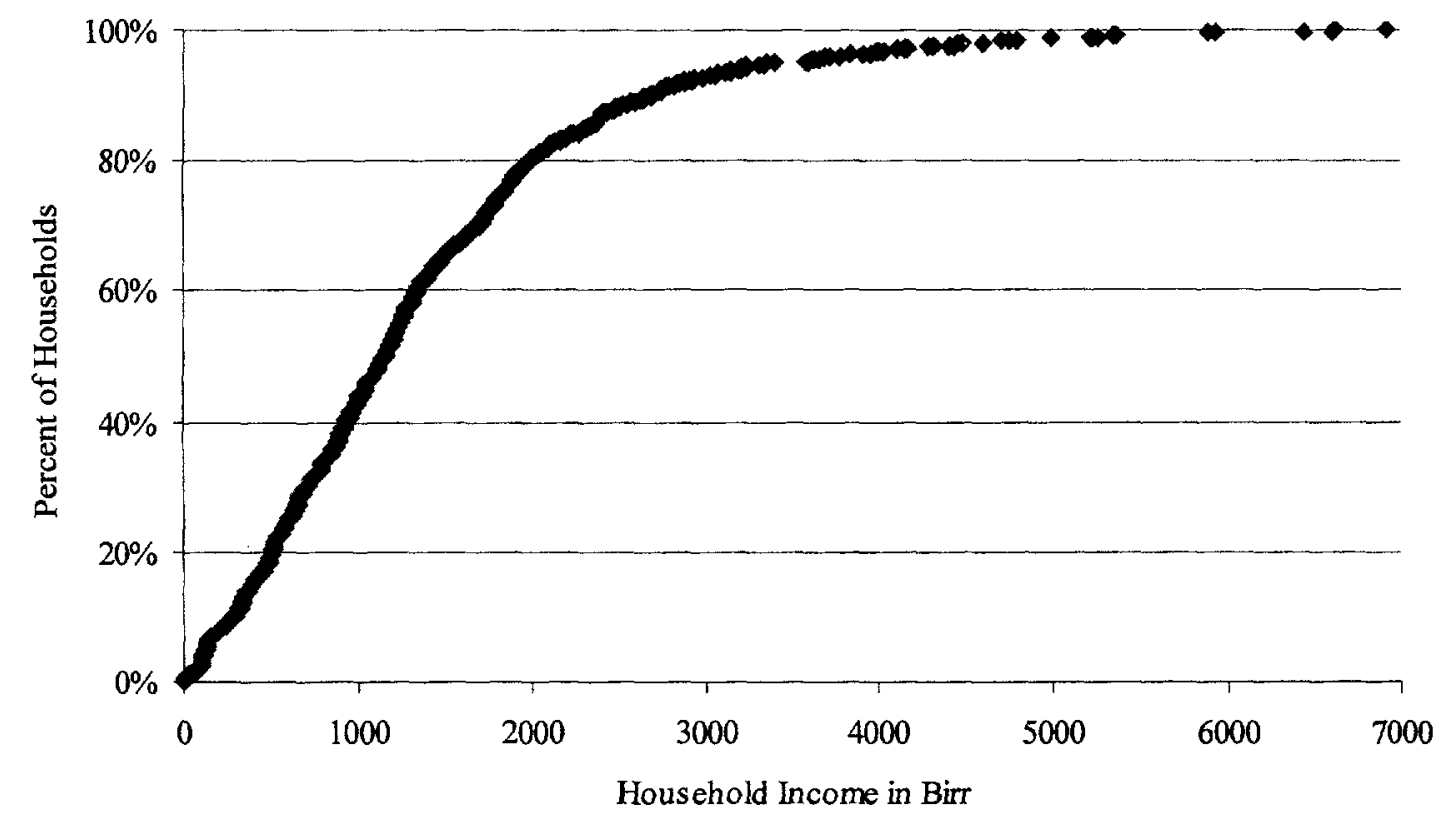

Figure 2. Lorenz Curve for Household Income

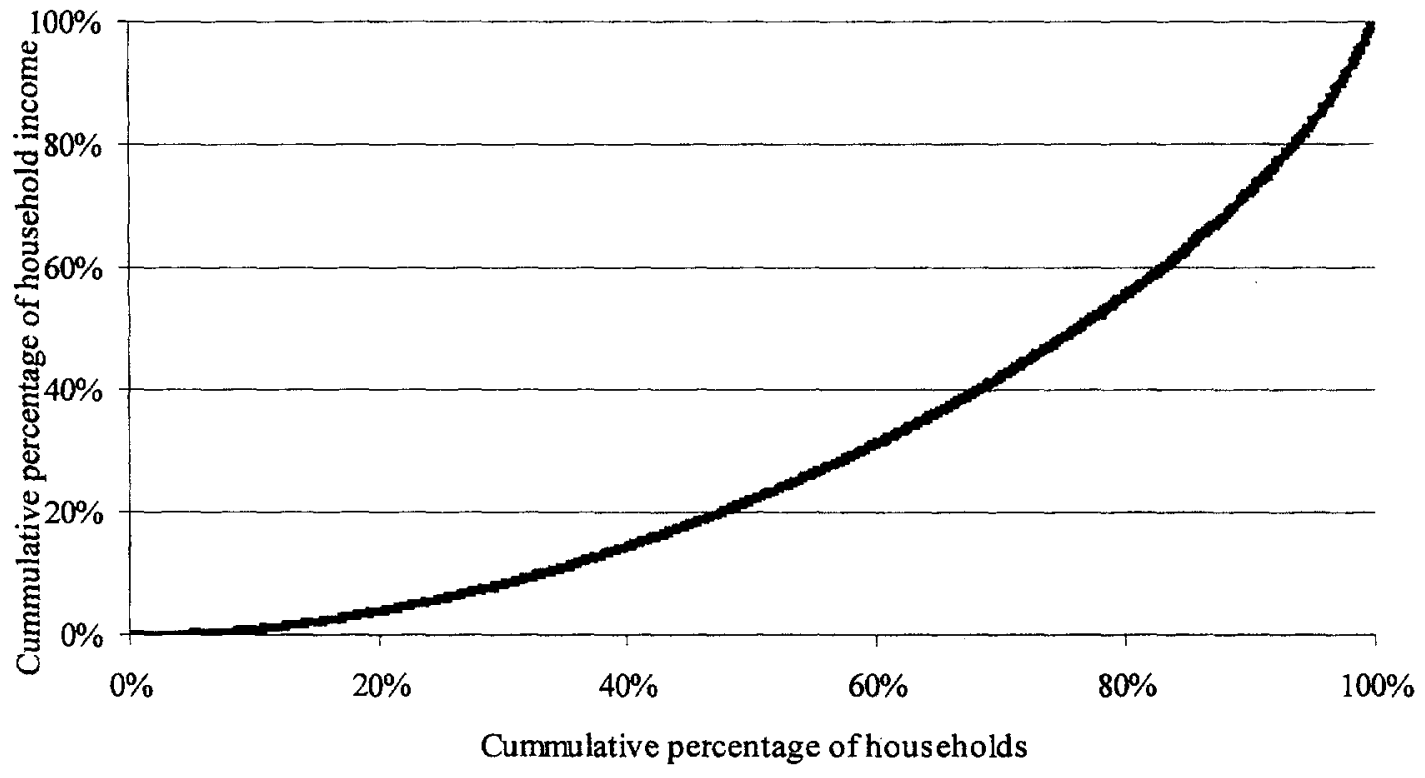


Figure 3. Household Demand Curve for Vaccines and WTP for Total Prevention

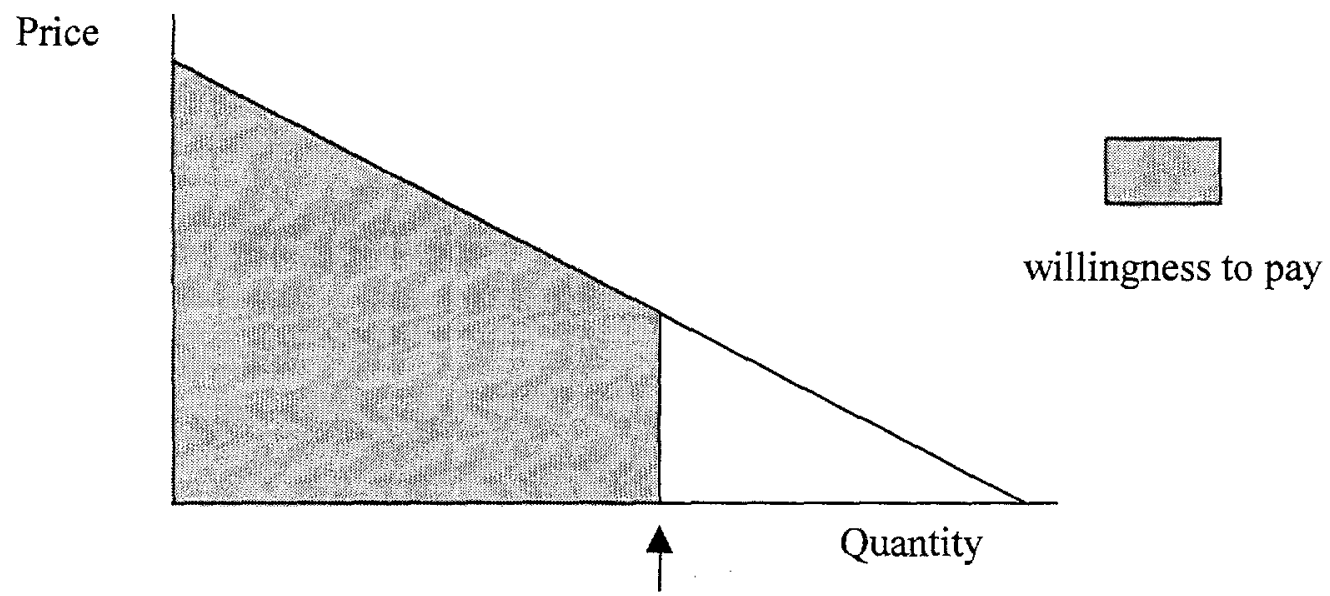

Household size

Figure 4. Number of Hypothetical Vaccines Purchased by Price

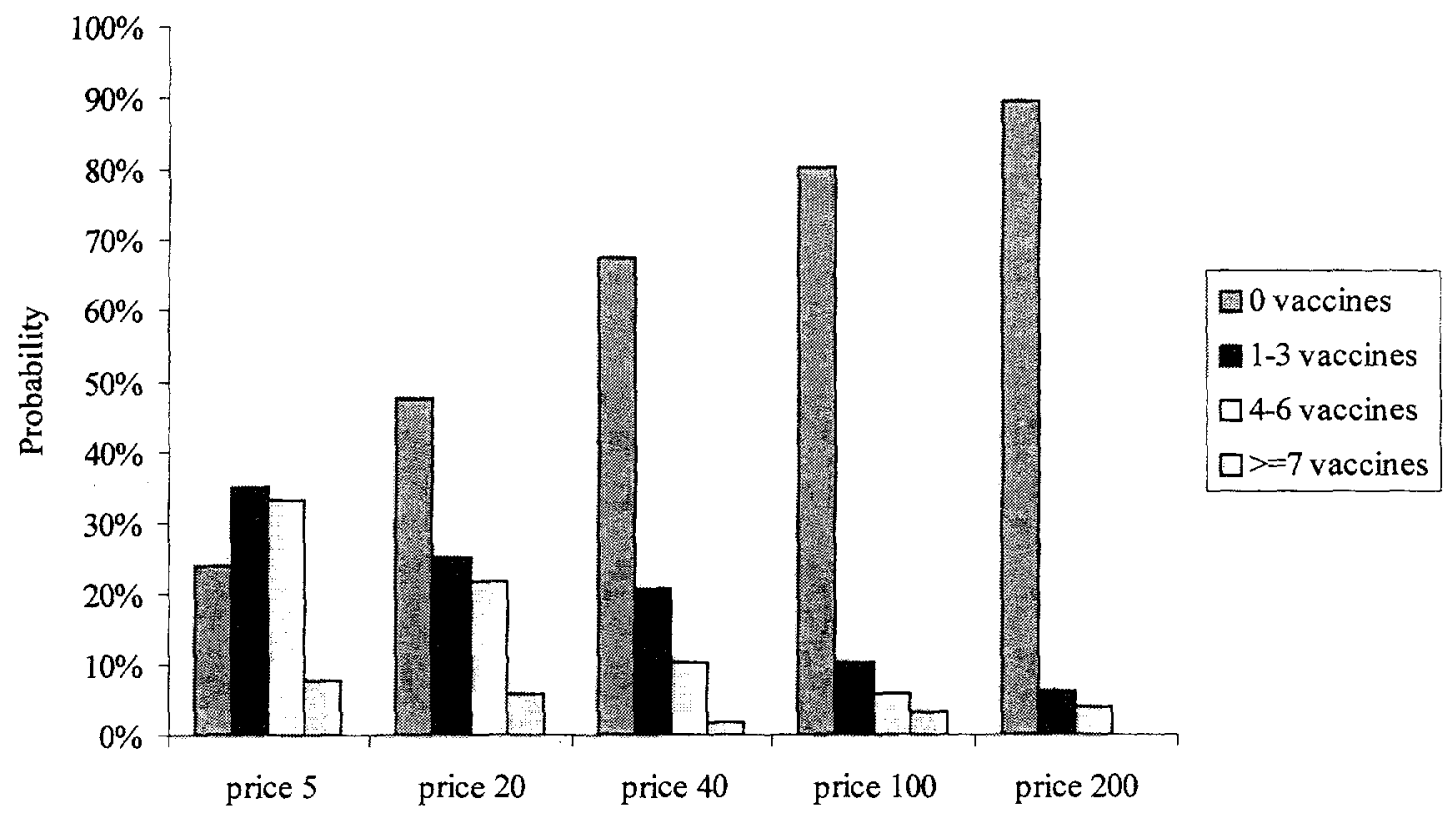


Figure 5. Malaria Vaccine Demand For 200 Household Village in Tigray, Ethiopia

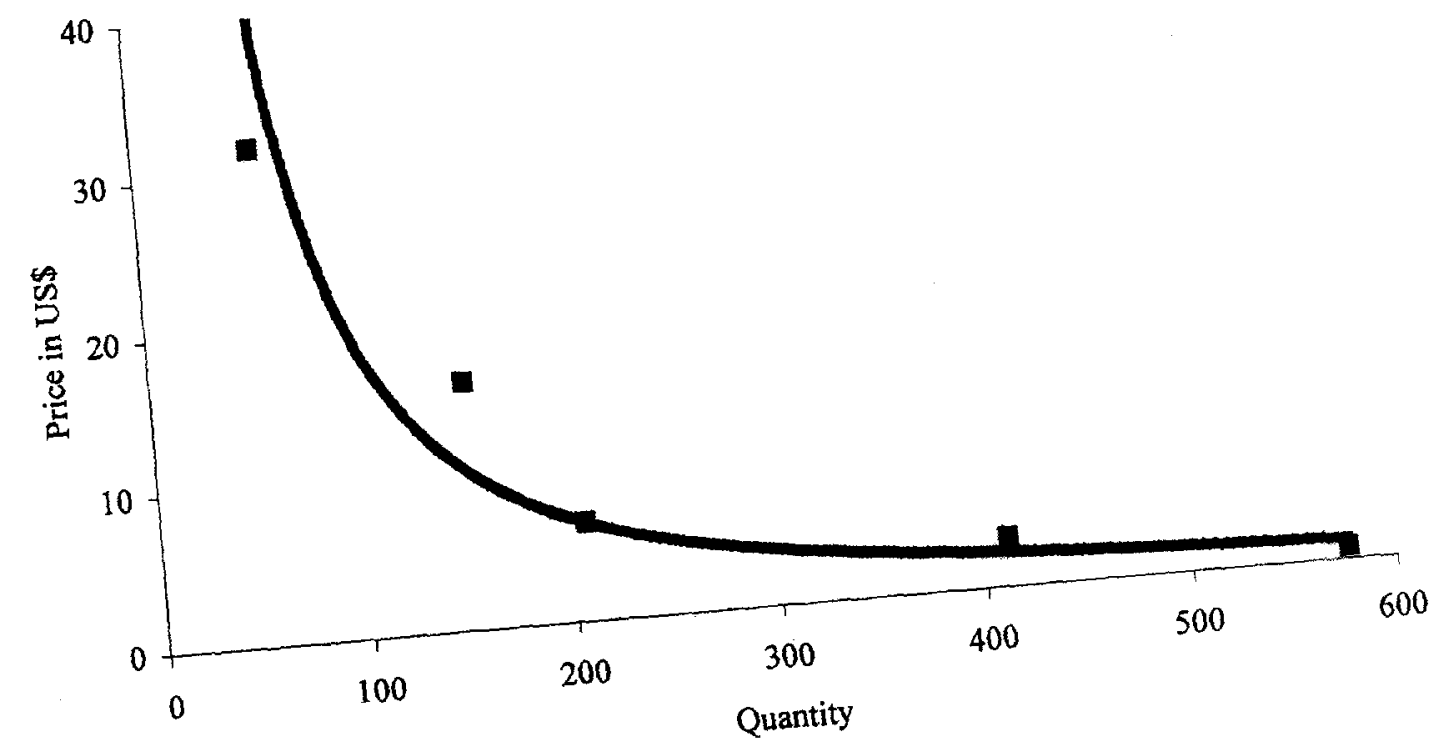

Figure 6. Percent of Income Spent on Vaccines at Different Prices in Tigray, Ethiopia

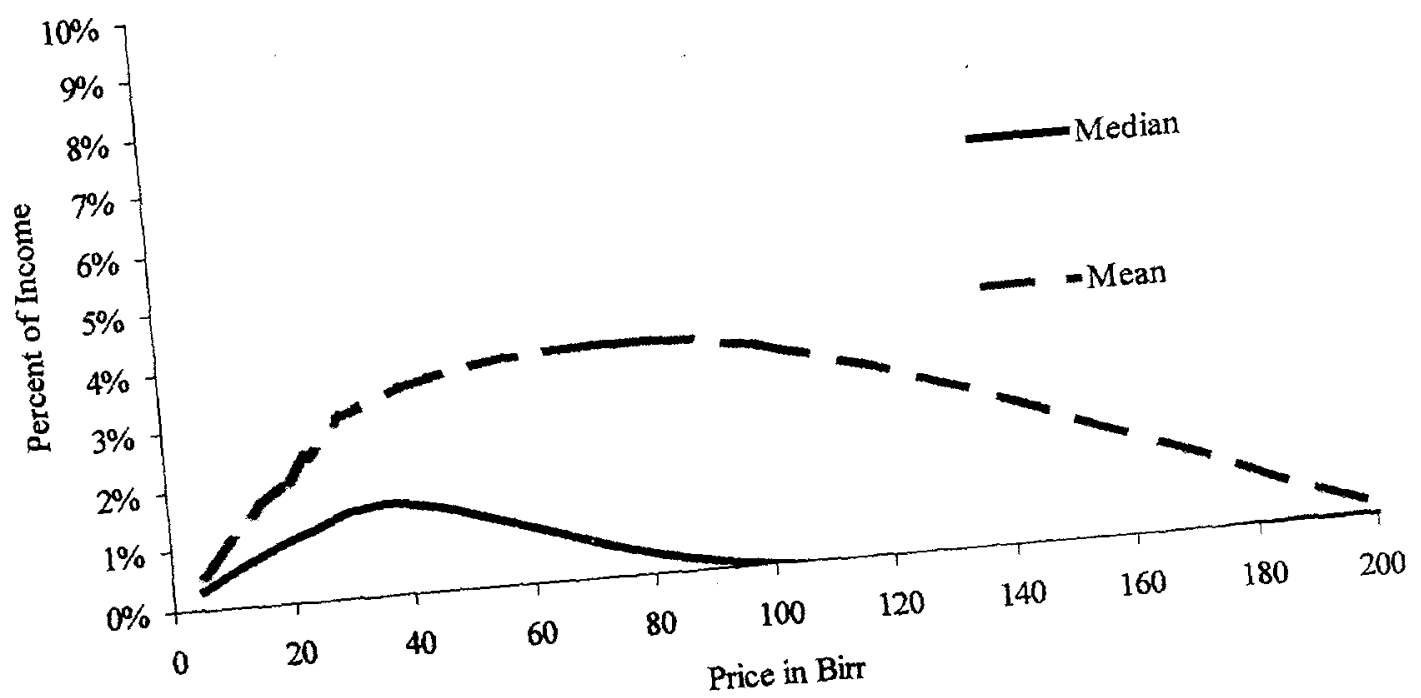


Figure 7. Distribution of Household WTP for Vaccines

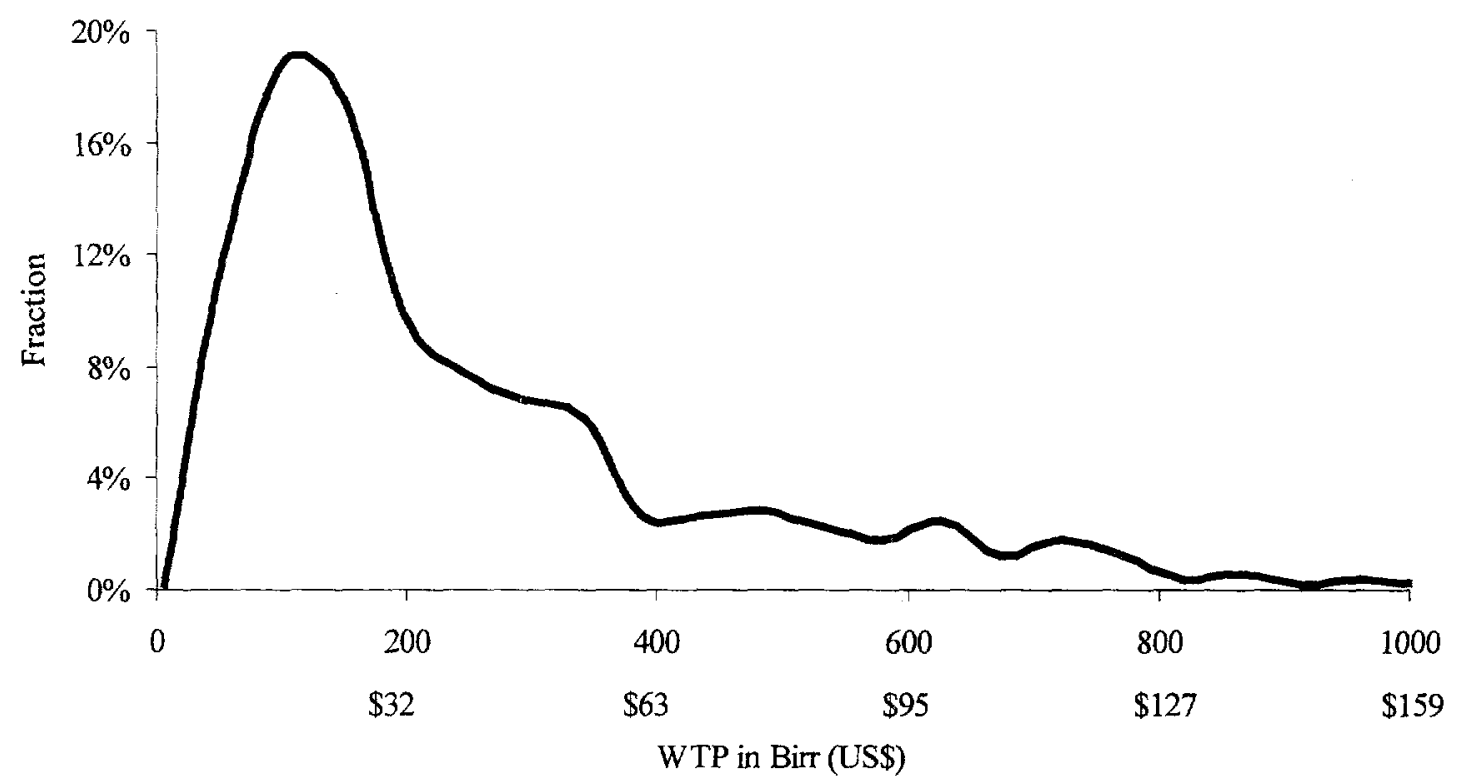

Figure 8. Probability of Purchasing Bednets at Different Prices

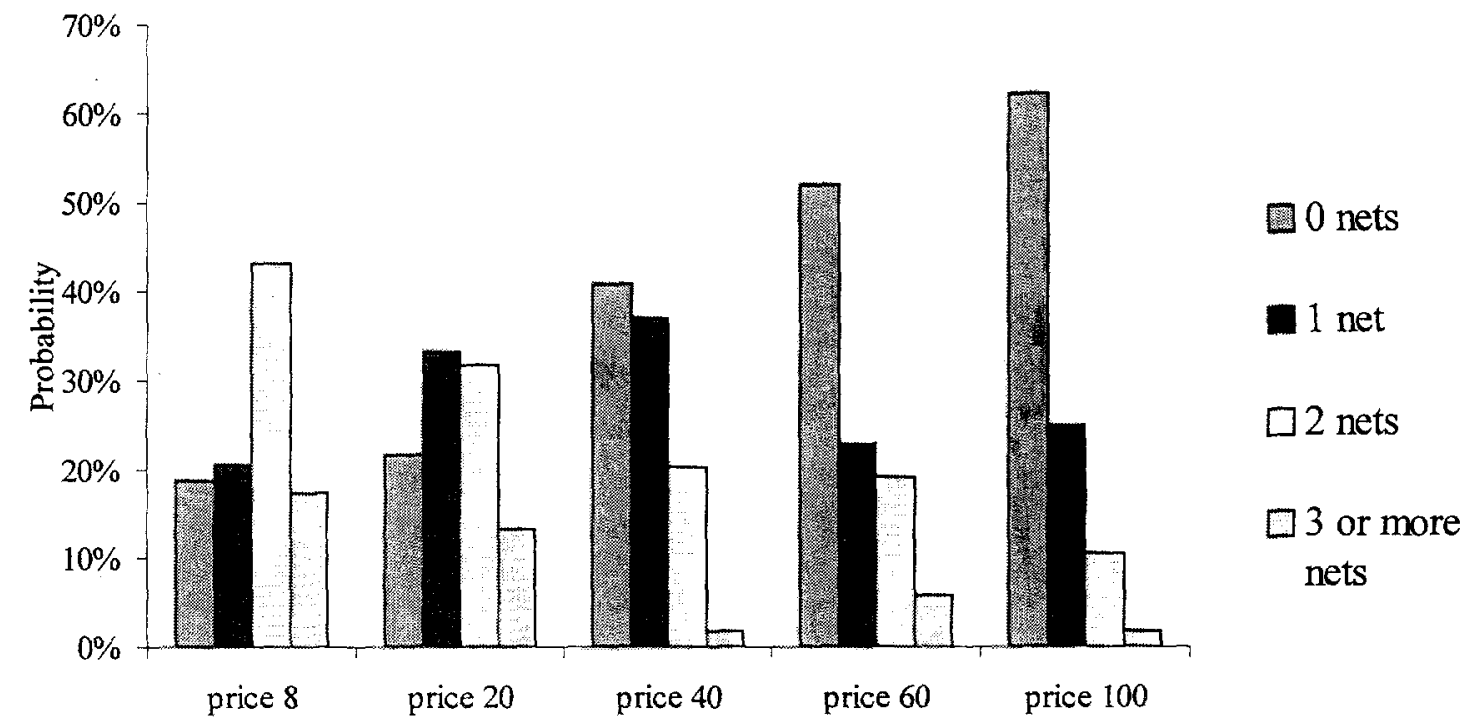


Figure 9. Demand for Bednets in 200 Household Village in Tigray, Ethiopia

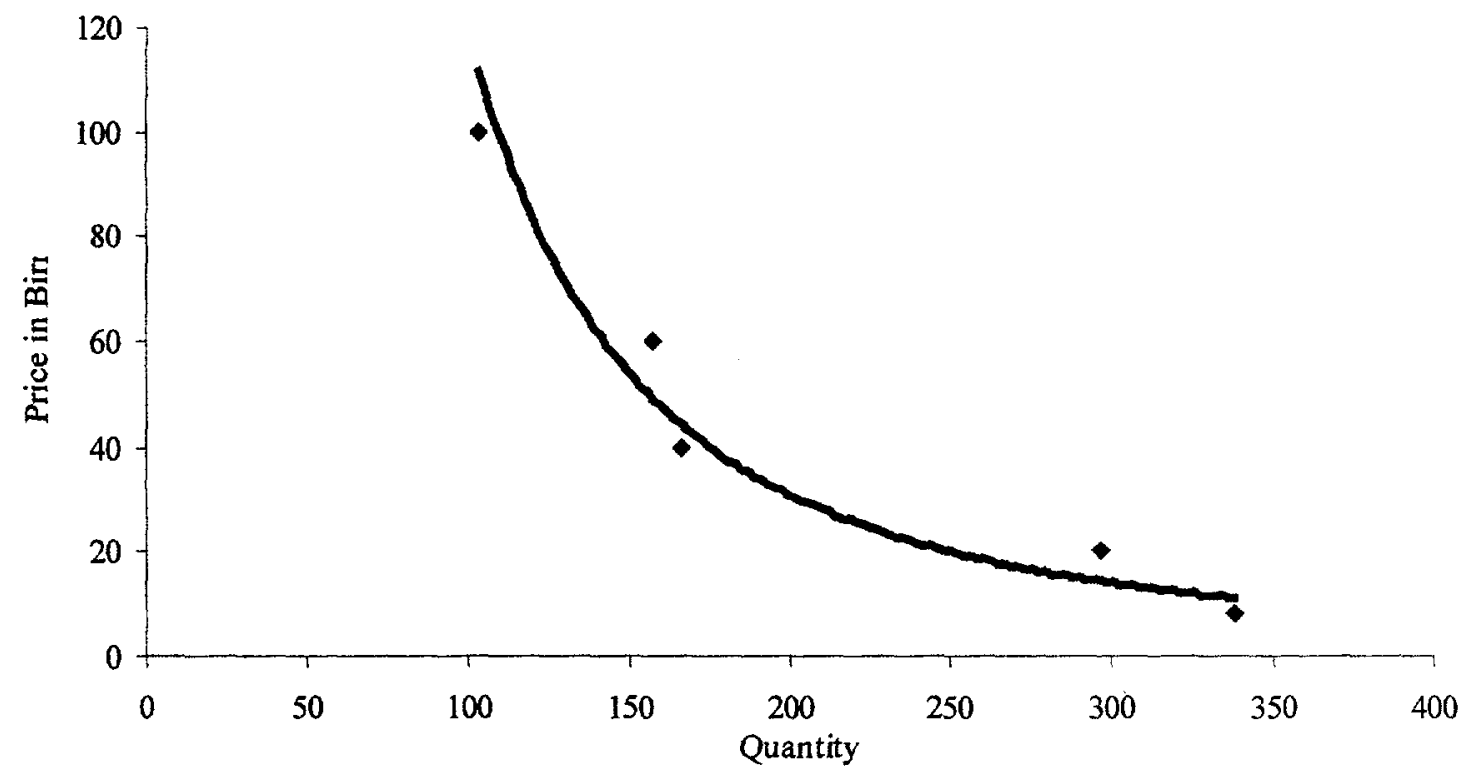


. 


\section{APPENDIX I: Household Questionnaire}

Name of Enumerator:

Date:

Time Start:

\author{
Version No: \\ Questionnaire No.: \\ Village Name:
}

\section{Introduction}

[Enumerator: Read the following introductory statement.] My name is and I am working on a survey about health issues in Tigray for the World Health Organization. We are interested in learning how people feel about different health problems. This research will help the government and donor agencies select the health policies for Tigray that people most want. We are interviewing many different communities and households in Tigray. The interview will be completely confidential, and if at any time you wish to stop the interview or not answer a specific question, this is entirely up to you. The interview will take less than one hour.

1.. Would you be willing to be interviewed?

(0) No (STOP THE INTERVIEW)

(1) Yes

2.. Are you the head of the household or the spouse of the head of the household?

(0) No (STOP THE INTERVIEW)

(1) Yes

[Note: Only the head of household, or his/her spouse should be interviewed.]

3. [Enumerator: What is the gender of the respondent?]

(0) Male

(1) Female

4.. How many people live in this household, including yourself?

No. of individuals

5.. How many adults (greater than or equal than 18 years) live here?

No. of adults

6. How many teenagers ( $12-17$ years) live here?

No. of teenagers

7. How many children 11 years or younger live here?

No. of children

(Enumerator: Add the responses to questions 5, 6, and 7 and check that the sum is the same as the response to question 4)

Total of questions 5,6 , and 7

\section{Social Priorities}

8. I am going to read a list of projects that the government could implement if it received more foreign aid. Which one would you most prefer the government to spend money on? [Enumerator: Place tick next to the first choice. Mark only one response]

(1) Increase supply of drugs for health clinic

(2) Increase the supply of supplies, books and equipment for the schools.

(3) Ensure an adequate, safe drinking water supply for each household in Tigray.

(4) Increase malaria control programs.

(5) Improve credit programs. 
(6) Provide irrigation systems to water crops.

(-98) Don't know/Not sure

\section{Health history}

\section{3-a . Health status}

9.

How would you describe your health compared to the health of other people your age in this village?

(2)Much better

(1)Better

(0) About the same

(-1) Worse

(-2) Much worse

(-98)Don't know/Not sure

10. Do you have a chronic illness (an illness that lasts a long time and/or comes back frequently)?

(0) No

(1) Yes

(-98) Don't know/Not sure

11. What do you think is the most important disease in your village? [Enumerator: Do not read list of responses. Record first response only. Mark only one.]

(1) Malaria

(2) Tuberculosis

(3) Respiratory problems, not including tuberculosis (for example, asthma or bronchitis)

(4) Diarrhea

(5) Eye Disease

(6) Malnutrition

(7) Cancer

(8) Meningitis

$(-95)$ : Other (please specify)

$(-98)$ Don't know/Not Sure

12.Do you have free papers for medical care?

(0) No

(1) Yes

13. Do you have to pay for examination fees if you see a health worker at the nearest health clinic? (0) No (GO TO QUESTION 15)

(1) Yes

(-98) Don't know

14. How much would you have to pay in examination fees to see a health worker at the nearest health clinic?

Birr

$(-98)$ Don't know/Not Sure

15. Do you have to pay for medicine when you need it?

(0) No (GO TO SECTION 3-B)

(1) Yes

(-98) Don't know

16. How much would you have to pay for medicine if you need it?

Birr

(-98) Don't know/Not Sure 
3-b. Respondent malaria knowledge

Now I would like to ask you what you know about the sickness known as malaria?

[Enumerator: In this section, do not read the responses. Let the respondent answer the question. If the response is $i$ the list below, place a tick mark next to the response. If the response is not in the list below, write the response in "Other"]

17. Do you know what malaria is?

(0) No (GO TO SECTION 3-E)

(1) Yes

18. How is malaria transmitted? [Enumerator: Do not read list. Place tick marks next to all that apply.]

a. Mosquitos

b. Lack of sanitation

c. Impure water

d. Wet places

e. Other:

f. ___ Don't know/Not sure

19. What are the symptoms of malaria? [Enumerator: Do not read list. Place tick marks next to all that apply.]

a. Fever

b. Shivering

c. Convulsions

d. Headache

e. Backache

f. Anemia

g. Stomachache

h. Vomiting

i. Diarrhea

j. Joint pain

k. Loss of appetite

1. Other:

m. Don't know/Not sure

20. Is malaria more serious for adults or for children?

(1) Adults

(2) Children

(3) Equally serious for adults and children

(4) Not serious for adults or children

(-98) Don't know/Not sure

21. If someone is sick with malaria, what are the best ways to cure this person? [Enumerator: Do not read list. Place tick marks next to all that apply.]

a. No treatment is necessary

b. Taking chloroquine

c. Taking other medicine (please specify)

d. Injections

e,_Cupping

f.___ Fumigation

g. Changing one's diet

h. Cleaning house, environment, or body

i.__ Religious healing: Holy water, debtera

j. Herbal medicines

k. Other:

1. Don't know/Not sure 
22. What are the best ways to avoid getting malaria? [Enumerator: Do not read list. Place tick marks next to all that apply.]
a. There is no way to prevent malaria
b. _Cleaning the house or environment, including draining wet areas
c. Sleeping under a bednet
d. Taking chloroquine
e. Taking other medicine (please specify)
f._Eating a special diet(includes avoiding certain foods)
g. Burning leaves, dung, and other materials
h. Spraying insecticides
i. Other
j. Don't know/Not sure

\section{3-c. Respondent Malaria History}

Now I would like to talk with you about malaria.

23. Have you ever had malaria?

(0) No (GO TO SECTION 3-D)

(1) Yes

(2)Had fever, but doesn't $k$ now if had malaria (GO TO SECTION D)

24 . Did you get malaria in this village or somewhere else?

$(0)$ In this village

(1) Somewhere else

(-98) Don't know/Not sure

25. How did you know that you had malaria? (Enumerator: Mark first response only.)

(1) Medical tests

(2)Community health worker told me

(3)Traditional healer told me

(4)I recognized the symptoms myself as being those of malaria

(5) A family member told me that I had malaria

(-98)Don't know / Don't remember

26. How many times have you had malaria over the past two years?

No. of times

[Enumerator: If zero, GO TO SECTION 3-D]

Now I want to talk with you about that most recent episode.

27. When was the last time you had malaria?

(1) Kiremti (June-September)

(2) Kawie (October -November/December)

(3) Hagai (December - March)

(4) Belgi/Asmera (April - May)

a. 198 _ Year (Ethiopian calendar)

28. How many days were you sick with malaria?

No. of days :

(-98) Don't know

29. Did you stop working?

(0) No (GO TO QUESTION 38)

(1) Yes 
30. How many days did you miss work?

No. of days

(-98) Don't know

31. Did someone do your work for you?

(0) No (GO TO QUESTION 35)

(1) Yes

(-98) Don't know/Not Sure (GO TO QUESTION 35)

32. Was this person an adult, teenager, or a child?

(1) Adult (equal to or greater than 18 years old)

(2)Teenager (11-17 years old)

(3) Child (less than or equal to 10 years old)

(-98) Don't know/Not Sure

33. Did the person who worked in your place cut back on their own duties?

(0) No (GO TO QUESTION 3 5)

(1)Yes

(-98) Don't know/Not Sure

34.How many days did this person cut back on their own duties?

No. of days

(-98) Don't know/Not Sure

35. Were you so sick that someone had to cut back on their own duties for one or more days just to care for you?

(0) No (GO TO QUESTION 38)

(1)Yes

(-98) Don't know/Not Sure

36. Was this person an adult, teenager, or a child?

(1) Adult (equal to or greater than 18 years old)

(2) Teenager (11-17 years old)

(3) Child (less than or equal to 10 years old)

(-98) Don't know/Not Sure (Go to question 38)

37. How many days did this person cut back on their own duties just to care for you?

No. of days

(-98) Don't know/Not Sure

38. Did you seek treatment for malaria?

(0) No (GO TO SECTION 3-D)

(1) Yes

39. What treatment did you first seek? [Enumerator: Do not read list. Mark first response only.] (If the respondent says "doctor," ask where the doctor is found. For example, in the clinic or hospital)

(1) Traditional medicines: holy water, debtera, prayer, habamesh medicine, herbal medicines

(2) Went to the clinic

(3) Went to the pharmacy only

(4) Went to the Community health worker

(5) Went to the hospital

(6) Clean the environment (GO TO SECTION 3D)

(-95) Other (specify:)

(GO TO SECTION 3-D) 
40. How much did it cost to receive this treatment not including the cost of transportation? (If payment was made in other goods besides Birr, please specify the type of good, the unit it is measured in, and the amount they used in payment.)

a. Birr

(-98) Don't know/Not Sure (GO TO QUESTION 42)

If payment is in kind

b.

c. type of good

unit

d. number of units

41. Does this cost include the cost of medicine?

(0) No

(1)Yes

(-98) Don't know/Not Sure

42. What kind of medicine did you receive? (Enumerator: Mark first response only.)

(0)None

(1) Chloroquine

(2) Antibiotics

(3) Fansidar

(4)Quinine

(5) Herbal treament (specify:)

(-95) Other (specify):

(-98) Don't know

43. What form of tranportation did you take? (Enumerator: Choose all that apply.)

(1) Walk (GO TO QUESTION 45)

(2) Truck/Bus

(3) Cart

(4) Animal

(5) Stretcher

(-98)Other:

44. How much did transportation cost, in money or other things? (If payment was made in other goods besides Birr, please specify the type of good, the unit it is measured in, and the amount they used in payment.)

a. ___ Birr (GO TO QUESTION 45)

$(-98)$ Don't know/Not Sure

If payment in kind

b. ___ payment in kind: type of good

c. unit

d. number of units

45. How many hours did you travel one way to receive this treatment?

No. of hours

(-98) Don't know

46. Were you cured?

(0) No

(1) Yes

\section{3d. Malaria incidence and household malaria history}

(Enumerator: If at any point in this section, the respondent says that a family member has died of malaria, skip to question 3 ) 
Now I'd like to ask you about other adults in your household, besides yourself, and their experience with malaria.

47. Have any other adults is this household had malaria over the past two years?

(1) Yes

(0) No (GO TO QUESTION 50)

(-98) Don't know/not sure (GO TO QUESTION 50)

$(-97)$ There aren't other adults in this household (GO TO QUESTION 50)

48. In total, how many other adults had malaria over the past two years?

No. of adults

(-98) Don't know/not sure

(-99) Did not answer

49. Did these adults get malaria in this village or somewhere else?

(0) Somewhere else

(1) In this village___ (-98) Don't know

50. Have any of the teenagers or children in this household had malaria over the past two years?

(1) Yes

(0) No (GO TO SECTION 3E)

(-98) Don't know/not sure (GO TO SECTION 3E)

$(-97)$ There are no teenagers or children (GO TO SECTION 3E)

51. In total, how many teenagers and children in this household had malaria over the past two years?

No. of teenagers and children

(-98) Don't know/not sure

(-99) Did not answer

Now I am going to ask you about the last time one of your children had malaria.

52. When was the last time a teenager or child in this household had malaria? [Enumerator: If more than one teenager or child had malaria at the same time, please think of the youngest of the teenagers or children and answer the following questions about the last time he or she had malaria.]

(1) Kiremti (June-September)

(2) Kawie (October -November/December)

(3) Hagai (December - March)

(4) Belgi/Asmera (April - May)

a. 198 _ 198 _ Year (Ethiopian calendar)

53 . What is the gender of this teenager or child?

(0) Male

(1) Female

54. How old was the teenager or child?

years

55 . Did this teenager or child get malaria in this village or somewhere else?

(0) In this village

(1) Somewhere else

(-98) Don't know/Not sure

56. How many days did the malaria last?

No. of days

(-98) Don't know/not sure 
57.'Did he/she stop performing his/her normal duties?

(0) No (GO TO QUESTION 63)

(1) Yes

58. How many days did he/she miss his/her normal duties?

No. of days

59. Did someone else take over these duties?

(0) No (GO TO QUESTION 63)

(1) Yes

(-98) Don't know/Not Sure (GO TO QUESTION 63)

60. Was this person an adult, teenager, or a child?

(1) Adult (equal to or greater than 18 years old)

(2) Teenager (11-17 years old)

(3) Child (less than or equal to 10 years old)

(-98) Don't know/Not Sure

61. Did the person who took over these duties miss their own work?

(0) No

(1) Yes

(-98) Don't know/Not Sure

62. How many days did this person cut back on their own duties?

No. of days

(-98) Don't know/Not Sure

63. Did someone miss work just to care for the sick child/teenager?

(0) No (GO TO QUESTION 66)

(1) Yes

(-98) Don't know/Not Sure

64. Was this person an adult, teenager, or a child?

(1) Adult (equal to or greater than 18 years old)

(2) Teenager (11-17 years old)

(3) Child (less than or equal to 10 years old)

(-98) Don't know/Not Sure

65. How many days did this person miss work just to care for the sick teenager or child?

No. of days

66. Did you seek treatment for the sick teenager or child?

(0) No (GO TO SECTION 3E)

(1) Yes

67. What treatment did you seek first? [Enumerator: Do not read list. Mark first response only.]

(1) Traditional medicines: holy water, debtera, prayer, habamesh medicine, herbal medinicines

(2) Went to the clinic

(3) Went to the pharmacy only

(4) Went to the Community health worker

(5) Went to the hospital

(6) Clean the environment (GO TO SECTION 3E)

(-95) Other (specify:) (GO TO SECTION 3E)

68. How much did it cost to receive this treatment not including the cost of transportation? (If payment was made in other goods besides Birr, please specify the type of good, the unit it is measured in, and the amount they used in payment.) 
a. Birr

(-98) Don't know (GO TO QUESTION 70)

If payment in kind

b.

c.

d. type of good unit number of units

69. Does this cost include the cost of medicine?

(0) No

(1) Yes

(-98) Don't know/Not Sure

70. What kind of medicine did you get? (Enumerator: Do not read list. Mark first response only.)

(0)None

(1) Chloroquine

(2) Antibiotics

(3) Fansidar

(4) Quinine

(5) Herbal treament (specify:)

(-95) Other (specify:)

(-98) Don't know

71. What form of transportation did you take? (Enumerator: Mark first response only.)

(1) Walk (GO TO QUESTION $\underline{73}$ )

(2) Truck/Bus

(3) Cart

(4) Animal

(5) Stretcher

(6) Other:

72. In total, how much did transportation cost, in money or other things? (If payment was made in other goods besides Birr, please specify the type of good, the unit it is measured in, and the amount they used in payment.)

a. $\operatorname{Bir}$

(-98) Don't know/Not Sure

If payment in kind

b. ___ type of good

c. _unit

d. number of units

73. How many hours did you travel one way to receive this treatment?

No. of hours

(-98) Don't know

74. Was the teenager or child cured?

(0) No

(1) Yes (GO TO SECTION 3E)

(-98) Don't know

(Enumerator: If respondent provided the information to answer the next two questions, do not ask the questions, but answer the questions using information that they already gave you. If they did not answer these questions, then ask.)

75. Has anyone in your family ever died of malaria?

(0) No (GO TO SECTION 3E) 
(1) Yes

(-98) Don't know (GO TO SECTION 3E)

76.

How was that person related to you?

(1) Parent

(2) Brother or sister

(3) Spouse

(4) Child

(5)

Other: (please specify)

\section{3e. Avertive behaviors}

Do you normally do any of the following things to try to prevent malaria:

77. Do you normally take medicine before you get sick in order to prevent malaria?

(0) No

(1) Yes (GO TO QUESTION 79)

(-98) Don't know/Not sure (GO TO QUESTION 79)

78. Why not? (Enumerator: Mark first response only.)

(1) Too expensive

(2) Too time consuming/inconvenient

(3) Not applicable to me

(4) Not aware of it

(5) Not available

(6) Malaria not a problem where I live

(7) Not effective

$(-95))$

Other: (please specify)

79. Do you normally spray your house to kill mosquitoes? (Enumerator: This does not include spraying done by malaria control authorities.)

(0) No

(1) Yes (GO TO QUESTION 81)

(-98) Don't know/Not sure (GO TO QUESTION 81)

80. Why not? (Enumerator: Mark first response only.)

(1) Too expensive

(2) Too time consuming/inconvenient

(3) Not applicable to me

(4) Not aware of it

(5) Not available

(6) Malaria not a problem where I live

(7) Not effective

$(-95))$

Other: (please specify)

81. Do you normally drain areas of water near your house to prevent mosquitoes from breeding?

(0) No

(1) Yes (GO TO QUESTION 83)

(-98) Don't know/Not sure (GO TO QUESTION 83)

82. Why not? (Enumerator: Mark first response only.)

(1) Too expensive

(2) Too time consuming/inconvenient

(3) Not applicable to me

(4) Not aware of it

(5) Not available 
(6) Malaria not a problem where I live (7) Not effective

$(-95))$ Other: (please specify)

83. Do you normally burn dung or leaves to keep mosquitoes away?

(0) No

(1) Yes (GO TO QUESTION 85)

(-98) Don't know/Not sure (GO TO QUESTION 85)

84. Why not? (Enumerator: Mark first response only.)

(1) Too expensive

(2) Too time consuming/inconvenient

(3) Not applicable to me

(4) Not aware of it

(5) Not available

(6) Malaria not a problem where I live

(7) Not effective

$(-95))$

Other: (please specify)

85. Has the government sprayed your house and community with insecticides to kill mosquitoes in the last two years?

(0) No

(1) Yes

(-98) Don't know/Not sure

86. Does your community drain areas of standing water, including puddles, tree stumps, pots collecting water, and swamps, in order to control mosquito populations? (Enumerator: This includes only spraying done by Malaria Control.)

(0) No

(1) Yes, my community drains these types of areas

\section{Choice between Two Health Programs}

Suppose that the government of Tigray is considering two programs to rehabilitate and improve the hospital and to fight the main diseases here in Tigray.

Program A would save 100 lives in the next 12 months.

Program B would save $[200 / 500 / 1000]$ lives in $[2 / 5 / 10]$ years.

87. Assume the two programs cost the same but that there is money to implement only one of them. I would like to ask you which of the two programs you would choose, or which of the two programs you think should be implemented in Tigray.

(0) Program A (GO TO QUESTION 88)

(1) Program B (GO TO QUESTION 89)

(-98) Don't know / Didn't understand / Don't want to answer (GO TO SECTION 6)

88. Why did you choose program A? (Enumerator: Choose only one.)

(1) One should live day by day

(2) The future is uncertain

(3) The life I save may be my on (or my family is living now)

(4) Solve problems now

(5) Don't know

(6) Technology progress provides means to save people in the future

$(-95)$

(Enumerator: GO TO SECTION 6)

Other (please specify)

89. Why did you choose program B? (Enumerator: Choose only one.)

(1) Make the future better

(2) Future oriented program saves more lives 
(3) Other (Please specify)

(-98) Don't know

\section{Socio-economic profile}

Now I want to ask you some questions about your household.

\section{6a. Education}

90. How many years of education have you completed? (or, What is the highest level of education you have completed?) (Enumerator: Choose all responses that apply.)

(0) No schooling (grade)

(1) $1 \begin{array}{lllllll} & 2 & 3 & 4 & 5 & 6 & \text { Primary school }\end{array}$

(2) 78 Middle school

(3) $9 \quad 10 \quad 11 \quad 12$ Secondary school

(4) University

(5) Literacy Training

(6) Vocational School

(7) Church School

(-95) Other

(-98) Don't Know

91. Can you read a newspaper?

(0) No

(1) Yes, but with difficulty

(2) Yes, easily

92. Are you married?

(0) No (single-or divorced) (GO TO QUESTION 97)

(1) Yes

93. Is your spouse alive?

(0) No (GO TO QUESTION 97)

(1) Yes

94. How many years of education has your spouse completed? (or, What is the highest level of education your spouse has completed?) (Enumerator: Choose all responses that apply.)

(0) No schooling

$$
\text { (grade) }
$$

(1) $1 \quad 2 \quad 3 \quad 4 \quad 5 \quad 6$ Primary school

(2) 78 Middle school

(3) $9 \quad 10 \quad 11 \quad 12$ Secondary school

(4) University

(5) Literacy Training

(6) Vocational School

(7) Church School

$(-95)$ Other

(-98) Don't Know

95. Can your spouse read a newspaper?

(0) No

(1) Yes, but with difficulty

(2) Yes, easily

\section{6b. Occupation}

96. What is your spouse's primary occupation during the year? 
(0) Unemployed

(1) Farmer

(2) Agricultural labourer

(3) Non-agricultural labourer

(4) Skilled labourer/tradesman - e.g. carpenter

(5) Small Trader

(6) Civil servant

(7)Soldier

$(-95)$

Other (specify type of work)

97. What is your primary occupation during the year?

(0) Unemployed

(1) Farmer

(2) Agricultural labourer

(3) Non-agricultural labourer

(4) Skilled labourer/tradesman - e.g. carpenter

(5) Small Trader

(6) Civil servant

(7)Soldier

(-95) Other (specify type of work)

6c. Housing

98. How many rooms does this respondent's dwelling unit have?

No. of rooms

99. ?How many buildings are there in this compound?

No. of buildings

100. How many households live in this compound?

No. of households

101. Do you own or rent this house/flat?

(0) Rent (GO TO QUESTION 103)

(1) Own

102. If I want to sell a house like yours, how much can I sell it for?

(Birr (GO TO QUESTION 104)

(-98) (Don't know (GO TO QUESTION 104)

(-99) (Refused to answer (GO TO QUESTION 104)

103. What is your monthly rent?

Birr

104. [Enumerator: If this village does not have electricity, go to section 6D]

105. Does this house have electricity?

(0) No (GO TO SECTION 6D)

(1) Yes

106. How much was your last household electric bill?

Birr per month

(-98) Don't know

a. (1) ((Electricity is included in rent)

107. ((IF THE ELECTRIC BILL IS SHARED), What is your household's share of the electric bill? Birr per month 


\section{6d. Cooking}

108. What is the main fuel you use for cooking? (Enumerator: Do not read list. Tick only one response.)

(1) Dung

(2) Firewood

(3) Crop residue

(4) Kerosene

(5) Charcoal

(6) Electricity

Other (please specify)

\section{6e. Credit market}

109. If you wanted to borrow 100 Birr from a local money lender for one month (not from a family member), how easy would this be?

(0) Quite easy to do

(1) Possible, but not easy

(2) Impossible (GO TO QUESTION 111)

(-98) Not Sure (GO TO QUESTION 111)

110. How many Birr would you have to pay in addition after one month? Birr (additional)

$(-98)$ Not Sure

111. Have you done any of the following in the last year? (CHECK ALL THAT APPLY)

a. deposited cash in a bank

b. deposited cash with the REST credit scheme

c. ___ purchased livestock with the intention of selling them in the future for more money

d. ___ sent your children or other members of the household (including adults) to school or training classes

e. None

112. Have you borrowed money from the following sources in the last year? (CHECK ALL THAT APPLY)

a. Family/friends

b. moneylender

c. bank or credit institution

d. $\longrightarrow$ None

Credit

113. I want you to suppose that a private rural bank opened in [name of nearby town to take make loans. Suppose that the bank were willing to make you a loan of 100 Birr. You would be required to pay back $[150,200,350]$ Birr in $[1,2,5]$ years, in order to pay back this loan. Under these loan conditions, and given your current situation, would you want to borrow $100 \mathrm{Birr}$; or would you prefer not to borrow?

Yes, I would borrow 100 Birr now, and repay $[100,200,350]$ Birr in $[1,2,5]$ (GO TO QUESTION 114) No, I would not borrow 100 Birr now (GO TO QUESTION 115)

Don't know/Not sure (GO TO SECTION 6F)

114. If yes, why?

a. Lower repayment than other sources

b. I can't borrow from anywhere else

c. Other (please specify):

\section{(GO TO SECTION 6F)}

115. If no, why not? 

a. The loan is too small
b. ___ The amount I would repay is too much
c. I I would prefer not to spend more money than I have right now
d. I don't believe that the bank would lend to me
e. I I would rather borrow money from somewhere else
f. ___ Other (please specify):

\section{6f. Weekly expenditures}

Next I'd like to ask you about things you spend your money on each week.

116. About how much of your household's food do you grow yourself?

(0) Very little/none

(1) About half

(2) Almost all

(-98) Don't know

117. About how much money does your household spend per week on food (not including own production)?

Birr per week

(-98) Not Sure

\section{6g. Household Income}

118. How would you classify the economic status of your household relative to others in this village?

(2) Much better than most people (rich)

(1) Better than most people (relatively well off)

(0) About average

$(-1)$ Below average (poor)

(-2) Much worse than average (very poor)

(-98) Don't know

119. What was the off-farm income of all members of this household last year? (Note: Do not include income from agricultural products and include rental income if household rents rooms.)

Birr per year

$(-98)$ Don't know

120. Do you receive money from family members or friends who live outside of Ethiopia?

(0) No

(1) Yes

121. How many quintals of grain did you produce last year for each of the following crops:

a. SorghumNo. of quintals

b. ___ Finger millet No. of quintals

c. TeffNo. of quintals

d. WheatNo. of quintals

e. PulsesNo. of quintals

f. Oil cropsNo. of quintals

g. OtherNo. of quintals

122. Over the next five years, how do you think your household's economic situation will change?

(2) Certainly improve greatly

(1) Probably improve somewhat

(0) No change

(-1) Probably decline somewhat

(-2) Certainly get much worse

(-98) Don't Know / Not sure 
Do you agree or disagree; or, are you neutral about the following statements:

123. If I take care of myself, I can avoid illness

$(-1)$ Disagree

(0) Neutral

(1) Agree

124. Do you live pretty much for today and let tomorrow take care of itself?

$(-1)$ Disagree

(0) Neutral

(1) Agree

(-98) Don't know

125. Do you believe that it is not always wise to plan too far ahead because things turn out to be a matter of good or bad luck?

$(-1)$ Disagree

(0) Neutral

(1) Agree

(-98) Don't know

\section{6h. Household Assets}

(Enumerator: In each category, indicate the number of items owned by the respondent. If household does not have an item, enter zero.)

Could you tell me if someone in your household owns a(n) (category name)? (If YES), How many do you (he, she) own?

Animals:

126.

127.

128.

129.

130.

131.

132.

133.

134.

135. Chickens Goats

Sheep

Oxen Other Cattle

Donkey

Household Goods:

136. K__ Kerosene lamp

137. Coleman latern with pump

138. Beds

139. Radio

140. Bicycle

141. What is your religion?

(1) Christianity

(2) Islam

(3) Judaism $(-95)$ Jother (specify)

142. How old are you? years

7. Debriefing Questions 
143.a When I described to you the bednet impregnated with insecticide, I said that it would reduce the chance of you getting malaria if you used it properly. When you answered the question about purchasing the bednet, did you assume that this was really possible?

(0) Not at all possible

(1)Assumed it was possible

(-98)Didn't know, not sure not possible

143b. Now I want you to think about which kind of protection from malaria is more effective. There is no right or wrong answer, I really want to know what you think. Suppose that you had the choice between a bednet and a spraying program. Which one would you choose and why?

(0) Bednet

(1) Spraying program

(-98) Assumed it was possible

143c. Why?

Could you tell me the average price of the following items in this village at the present time?

144. Charcoal (30-40 kilogram sack)

145. Goat

146._Sheep

147. Ox

148. Sugar

149. Coffee

150.___ Cooking oil (1 liter)

151. Chicken (live)

152.

153. local beer

154. local beer

155. Bottle of beer

156. Cola or other soft drink (not imported)

157. 11 liter of kerosene

158. Pack of Cigarettes

159. 1010 tablets of chloroquine

160. At this time, what is the daily wage rate for an unskilled, healthy laborer here in .. (e.g., a construction or farm worker)?

Birr per day

\section{(-98) Don't know}

In this survey, I have asked you if you would be willing to pay for a method to protect you from getting malaria. As you may know, we are interviewing other people in your community and asking them the same question. However, some people in your community may have been asked if they would be willing to pay for the method at a different price than you were asked. We are asking people to respond to different prices to see how they would respond. Do not worry that you might have been asked a higher or lower price than someone else who participated in our study.

This is the end of our interview. Thank you very much for your time and assistance.

161. Time ended:

FOR ENUMERATOR ONLY:

(Enumerator: Do not ask respondent these questions. Observe and answer yourself.) What material(s) were used to build the main house? (Check all that apply.) 
162. Walls:

(1) Stone

(2) Wood

(3) Cement blocks

(4) Bricks

(5) Mud

(6) Metal

$(-95)$

JOther (specify:

163. Floor:

(1) Flat stones

(2) Concrete

(3) Dirt / Mud

$(-95)$

JOther (specify)

164. Roof:

(1) Corrugated iron

(2) Thatching materials

(3) Wood and timber (local type)

(4) Mud

$(-95)$

JOther (specify)

165. (If the house does have windows) Do any windows have glass panes?

(0) No

(1) Yes

166. What kind of door does the house have?

(1) Wooden

(2) Metal

$(-95)$ Other

167. Does the door have a lock?

(0) No

(1) Yes

Assessment of the interview

168. Was the person who answered the questions irritated or nervous during the interview?

(0) No

(1) Yes

169. Do you think the respondent made an effort to tell the truth about the willingness-to-pay questions?

(0) No

(1) Yes

170. How would you rate the overall quality of the interview?

(1) Good

(0) Fair

$(-1)$ Poor

171. How many adults were listening while you conducted this interview with the respondent?

No. of adults 


\section{Vaccine Scenario}

Now I would like to ask you what it would be worth to you to prevent getting malaria. For many years doctors have been working to develop a vaccine that would prevent people from getting malaria. A vaccine is a medicine that prevents a person from getting a disease. A person takes a vaccine before they get sick.

V1. Has anyone in your household ever received any type of vaccine?

(0) No (SKIP NEXT QUESTION)

(1) Yes

(-98) Don't know/Not sure (SKIP NEXT QUESTION)

What types of vaccines have they received? (Enumerator: check all that apply)

$\begin{array}{ll}\text { V2. } & \text { Small pox } \\ \text { V3. Cholera } & \text { Colio } \\ \text { V4. } & \text { Other }\end{array}$

Research for a malaria vaccine has not yet been successful; and there may never be a vaccine to protect against malaria. However, we would like to know what you would do if you could buy such a vaccine. Imagine that there is a vaccine for malaria even though this is not true.

Assume this vaccine would completely prevent you from getting malaria, and you would not need any other protection or treatment for malaria. You could have this vaccine as either a pill or injection and both would be completely effective against malaria. This means that you would not face the risk of missing work because of malaria or of having to buy medicine. You would not face the risk of fever or other symptoms of malaria.

Suppose it was possible for members of your household to get this vaccine. Assume that the government could not give the vaccine for free, so you would have to buy it.

Now I want to ask you whether your household would buy this vaccine against malariaif it were available for a price. There is no right or wrong answer. We really want to know what you think. Remember, the vaccine against malaria would completely prevent you from getting malaria for one year. After one year it would be necessary to buy and receive another vaccination to prevent getting malaria during the next year. Some people say that they would not pay for the vaccine because they have more important things to spend their money on, or because they feel they could prevent malaria in other ways. For example, they may spray their homes to kill mosquitoes or they may sleep under bednets.

This is a bednet [Enumerator: show bednet to respondent].

B1. Do you normally use a bednet?

(0) No

(1) Yes (SKIP NEXT QUESTION)

(-98) Don't know (SKIP NEXT QUESTION)

B2. Why not? (Enumerator: Mark first response only.)

(1) Too expensive

(2) Too time consuming/inconvenient

(3) Not applicable to me

(4) Not aware of it

(5) Not available

(6) Malaria not a problem where I live

(7) Not effective

$(-95)$

Other: (please specify) 
Other people say they would not buy the vaccine because they believe the malaria situation here is not so bad and if they got malaria, they could treat it by taking chloroquine. However, if you bought the vaccine you would not have to do other things to prevent or treat malaria and you would also avoid the pain and suffering of the sickness.

V6. Suppose the price of each vaccine against malaria was [5/20/40/100/200] Birr. Would your household buy one or more vaccines at this price?

(0) No (GO TO QUESTION V16)

(1) Yes

(-98) I don't really know/Not sure (GO TO SECTION 5)

V7. How many vaccinations would your household buy?

No. of vaccinations

V8. You said that your household would choose to buy vaccinations against malaria at [5/20/40/100/200] Birr per vaccinations. The vaccinations would cost your household a total of Birr.

Could your household really afford to pay this much?

\begin{tabular}{|r|c|c|c|c|c|c|c|}
\hline & 1 & 2 & 3 & 4 & 5 & 6 & 7 \\
\hline Price $=5$ & 5 & 10 & 15 & 20 & 25 & 30 & 35 \\
\hline Price $=20$ & 20 & 40 & 60 & 80 & 100 & 120 & 140 \\
\hline Price $=40$ & 40 & 80 & 120 & 160 & 200 & 240 & 280 \\
\hline Price $=100$ & 100 & 200 & 300 & 400 & 500 & 600 & 700 \\
\hline Price $=200$ & 200 & 400 & 600 & 800 & 1000 & 1200 & 1400 \\
\hline
\end{tabular}

(0) No

(1) Yes (GO TO V10)

(-98) Don't know/not sure (GO TO SECTION 5)

V9. How many vaccinations would you buy?

No. of vaccinations

V10.How confident are you that you would really buy this many vaccinations?

(0) Not at all sure

(1) Somewhat sure

(2) Very sure

V11. How many of these vaccinations would be for adults in your household? Number of vaccinations for adults

V12. How many of these vaccinations would be for teenagers in your household? Number of vaccinations for teenagers

V13. How many of these vaccinations would be for children in your household? Number of vaccinations for children

V14. How would you are members of your household prefer to take the vaccine: by pill or by injection?

(1) By pill

(2) By injection

(3) Respondent is indifferent (GO TO SECTION 5)

(-98) Don't know (GO TO SECTION 5)

V15. Why?

[ 


\section{GO TO SECTION 5}

V16. How confident are you that you would really not buy the vaccination?

(0) Not at all sure

(1) Somewhat sure

(2) Very sure

V17. Why would you not buy the vaccination? [RECORD RESPONSE.]

\section{[The following debriefing questions will appear at the end of the questionnaire.]}

V18. When I described to you the vaccine against malaria, I said that it would be 100 percent effective in preventing malaria for one year. When you answered the question about purchasing the vaccine, did you assume that this was really possible?

(0) Not at all possible

(1) Assumed it was possible.

(-98) Didn't know / Not sure 


\section{Bednet Scenario}

Now I would like to ask you what it would be worth to you to prevent getting malaria. One way that malaria can be prevented is by sleeping under a bednet. This is a bednet [Enumerator: show bednet to respondent].

B1. Do you normally use a bednet?

(0) No

(1) Yes ( SKIP B2)

(-98) Don't know/Not sure

B2. Why not? (Enumerator: Mark first response only.)

(1) Too expensive

(2) Too time consuming/inconvenient

(3) Not applicable to me

(4) Not aware of it

(5) Not available

(6) Malaria not a problem where I live

(7) Not effective

$(-95)$

Other: (please specify)

Before I tell you about bednets, I want you to know that we do not have enough bednets to provide them to people in your village now. However, we are interested in whether people in this village would want to buy bednets. People hang the nets over their beds in their houses, just like in this picture [Enumerator: show picture]. By sleeping under the nets at night, people protect themselves from being bitten by mosquitoes and other insects. The net keeps the mosquitoes away from you. The bednet is even more effective when it has been soaked with a chemical that kills insects such as mosquitoes, bed bugs, lice and flies that get near the bednet. The insecticide on these bednets does not harm people and it lasts for about one year. Once a year the bednet must be soaked in insecticide again to make it effective. It is also important not to wash the bednet or the insecticide will be washed off. For bednets to be effective, people must stay under them from dusk until dawn, which is the time when mosquitoes that carry the malaria parasite are most likely bite. You may still catch malaria because you may be bitten by a mosquito when you are not under the net.

Do you have any questions? Yes/No [Enumerator: If yes, record the question(s) the respondent asked:]

Using a bednet reduces the chances of getting malaria and other diseases. Research in other parts of Africa has shown that bednets are particularly effective in reducing deaths among children. For example, in Kenya it was found that bednets reduced deaths among children by one third. That means that for every three children that would have died one was saved when they used bednets soaked in insecticide. It has also been found that families who use bednets have less sickness and do not have to spend as much money to prevent and treat malaria. Some households buy only one net and use it for the children. Some households buy only one net and use it for the adults. Other households buy more than one net. Suppose that people in your community could buy bednets impregnated with insecticide for a price. Now I want to ask you if your household would purchase one or more bednets if the Health Bureau were to deliver them to your village. This does not mean that other community control measures such as spraying insecticides will be stopped. There is no right or wrong answer; we really want to know what you think. Remember, the bednet will protect you only when you are sleeping under it. After one year it will be necessary to re-impregnate the bednet. This will cost about 5 birr each year and the bednet will last about 4 years. Some people say they would not pay for bednets because they have more important things to spend their money on, or because they feel they could prevent malaria in other ways. For example, they may take medicine before they get sick, or they may to spray their homes to try and kill mosquitoes. Other people would not buy bednets because they believe the malaria situation here is not so bad, and if they got malaria, they could treat it, for example, by taking chloroquine. However, if you bought bednets there is a good chance that you would not get malaria in the first place. Suppose that the price of a bednet was [8/20/40/100/160] Birr. You would pay for it in 4 equal payments. You would pay [2/5/10/25/40] Birr per month for 4 months, for a total of [8/20/40/100/160] Birr. 
B3. Would your household purchase any bednets if each bednet cost $[8 / 20 / 40 / 100 / 160]$ Birr?

(0) No(GO TO QUESTION B13)

(1) Yes

(-98) Don't know/not sure (GO TO SECTION 5)

B4. If yes, how many would your household buy?

No. of bednets

B5. You said that your household would choose to pay for

bednet, the bednets would cost your household a total of bednets. At [8/20/40/100/160] Birr per

Could your household really afford to pay this much? Birr or 4 equal payments of

(0) No

(1) Yes (GO TO B7)

B6. If no, how many bednets would you buy?

No of bednets (if 0 , GO TO SECTION 5)

B7. How confident are you that you would really buy this many bednets?

(0) Not sure at all

(1) Somewhat sure

(2) Very sure

B8. How many people in your household would sleep under these bednets?

No. of people

B9. How many of these are children?

No. of children

B10. How many of these are teenagers?

No. of teenagers

B11. How many of these are adults?

No. of adults

(Enumerator: Add the responses to questions $B 9, B 10, B 11$ and check that the sum is the same as the response to question B8)

Total of questions $B 9, B 10, B 1 I$

B12. What was the main reason that you decided to buy bednets?

(1) To prevent malaria

(2) To prevent diseases other than malaria

(3) To avoid being bothered by insects and other pests while sleeping

(4) For privacy

$(-95)$

Other

B13. How confident are you that you would really not buy bednets ?

(0) Not sure at all

(1) Somewhat sure

(2) Very sure

B14. You said you would not be willing to buy a bednet. Please tell me why [enumerator please record response].

[The following debriefing question will appear at the end of the questionnaire.] 
B. When I described to you the bednet impregnated with insecticide, I said that it would reduce the chance of you getting malaria if you used it properly. When you answered the question about purchasing the bednet, did you assume that this was really possible?

Not at all possible

Didn't know, not sure not possible

Assumed it was possible 


\section{APPENDIX II. Tables}

Table A1. Means and Standard Deviations of Variables, Vaccine Models

\begin{tabular}{lccccc}
\hline Variable & Obs & Mean & Std. Dev. & Min & Max \\
\hline Number of nets purchased & 569 & 1.45 & 2.19 & 0 & 10 \\
Price (Birr) & 569 & 68.30 & 68.22 & 5 & 200 \\
Log income (Thousand Birr) & 569 & 2.40 & 0.84 & -1 & 4 \\
Missing wage (1 if no wage) & 569 & 0.28 & 0.45 & 0 & 1 \\
Number of teenagers & 569 & 0.81 & 0.91 & 0 & 4 \\
Number of children & 569 & 1.95 & 1.35 & 0 & 6 \\
Household dir. cost of illness & 569 & 18.25 & 16.48 & 0 & 68 \\
(Birr) & & & & & \\
Married (1 if married) & 569 & 0.82 & 0.39 & 0 & 1 \\
Gender (1 if female) & 569 & 0.53 & 0.50 & 0 & 1 \\
Read (1 if read easily) & 569 & 0.38 & 0.49 & 0 & 1 \\
Age (years) & 569 & 42.56 & 14.25 & 17 & 95 \\
Alt (hundred meters) & 569 & 16.80 & 1.54 & 14 & 19 \\
Household size & 569 & 5.09 & 2.00 & 1 & 11 \\
\hline
\end{tabular}


Table A1. Means and Standard Deviations of Variables, Vaccine Models (continued)

\begin{tabular}{|c|c|c|c|c|c|}
\hline Variable & Obs & Mean & Std. Dev. & Min & Max \\
\hline HSIZE2 & 569 & 0.07 & 0.25 & 0 & 1 \\
\hline HSIZE3 & 569 & 0.12 & 0.32 & 0 & 1 \\
\hline HSIZE4 & 569 & 0.17 & 0.38 & 0 & 1 \\
\hline HSIZE5 & 569 & 0.20 & 0.40 & 0 & 1 \\
\hline HSIZE6 & 569 & 0.17 & 0.37 & 0 & 1 \\
\hline HSIZE7 & 569 & 0.14 & 0.34 & 0 & 1 \\
\hline HSIZE8 & 569 & 0.06 & 0.24 & 0 & 1 \\
\hline HSIZE9 & 569 & 0.04 & 0.21 & 0 & 1 \\
\hline Inam_2 & 569 & 0.03 & 0.18 & 0 & 1 \\
\hline Inam_3 & 569 & 0.04 & 0.20 & 0 & 1 \\
\hline Inam_4 & 569 & 0.09 & 0.29 & 0 & 1 \\
\hline Inam_5 & 569 & 0.08 & 0.27 & 0 & 1 \\
\hline Inam_6 & 569 & 0.09 & 0.28 & 0 & 1 \\
\hline Inam_7 & 569 & 0.08 & 0.27 & 0 & 1 \\
\hline Inam_8 & 569 & 0.03 & 0.18 & 0 & 1 \\
\hline Inam_9 & 569 & 0.04 & 0.20 & 0 & 1 \\
\hline Inam 10 & 569 & 0.04 & 0.19 & 0 & 1 \\
\hline Inam_11 & 569 & 0.09 & 0.28 & 0 & 1 \\
\hline Inam_12 & 569 & 0.04 & 0.20 & 0 & 1 \\
\hline Inam_13 & 569 & 0.04 & 0.19 & 0 & 1 \\
\hline Inam_14 & 569 & 0.04 & 0.19 & 0 & 1 \\
\hline Inam_16 & 569 & 0.04 & 0.20 & 0 & 1 \\
\hline Inam_17 & 569 & 0.10 & 0.30 & 0 & 1 \\
\hline Inam_18 & 569 & 0.05 & 0.22 & 0 & 1 \\
\hline Inam 19 & 569 & 0.04 & 0.20 & 0 & 1 \\
\hline
\end{tabular}


Table A2. Household Size and Enumerator Effects for Hypothetical Vaccine Models

\begin{tabular}{|c|c|c|c|}
\hline Variable & Poisson & Negative Binomial & Truncated Poisson \\
\hline DIhh_2 & $\begin{array}{c}0.757^{* *} \\
0.382\end{array}$ & $\begin{array}{c}1.000^{*} \\
0.546\end{array}$ & $\begin{array}{l}0.298 \\
0.594\end{array}$ \\
\hline DIhh_3 & $\begin{array}{c}0.838^{* *} \\
0.366\end{array}$ & $\begin{array}{c}0.887 * \\
0.541\end{array}$ & $\begin{array}{c}-0.106 \\
0.581\end{array}$ \\
\hline DIhh_4 & $\begin{array}{c}1.200^{* *} \\
0.377\end{array}$ & $\begin{array}{c}1.309 * * \\
0.579\end{array}$ & $\begin{array}{l}0.218 \\
0.588\end{array}$ \\
\hline DIhh_5 & $\begin{array}{c}1.148^{* *} \\
0.389\end{array}$ & $\begin{array}{c}1.295 * * \\
0.606\end{array}$ & $\begin{array}{c}0.110 \\
0.592\end{array}$ \\
\hline DIhh_6 & $\begin{array}{c}1.041^{* *} \\
0.423\end{array}$ & $\begin{array}{c}1.177^{*} \\
0.685\end{array}$ & $\begin{array}{c}-0.174 \\
0.608\end{array}$ \\
\hline DIhh_7 & $\begin{array}{c}0.677 \\
0.459\end{array}$ & $\begin{array}{l}0.820 \\
0.759\end{array}$ & $\begin{array}{c}-0.684 \\
0.623\end{array}$ \\
\hline DIhh_8 & $\begin{array}{c}1.180^{* *} \\
0.489\end{array}$ & $\begin{array}{c}1.391^{*} \\
0.833\end{array}$ & $\begin{array}{c}-0.094 \\
0.635\end{array}$ \\
\hline DIhh_9 & $\begin{array}{c}0.927 \mathrm{~b} \\
0.549\end{array}$ & $\begin{array}{l}1.225 \\
0.947\end{array}$ & $\begin{array}{c}-0.339 \\
0.660\end{array}$ \\
\hline Iname_2 & $\begin{array}{c}-0.368 \\
0.340\end{array}$ & $\begin{array}{c}-0.266 \\
0.520\end{array}$ & $\begin{array}{c}-0.309 \\
0.434\end{array}$ \\
\hline Iname_3 & $\begin{array}{c}0.898^{* *} \\
0.216\end{array}$ & $\begin{array}{c}1.366^{* *} \\
0.424\end{array}$ & $\begin{array}{c}1.689 * * \\
0.200\end{array}$ \\
\hline Iname_4 & $\begin{array}{c}-0.799 * * \\
0.247\end{array}$ & $\begin{array}{c}-0.833^{* *} \\
0.397\end{array}$ & $\begin{array}{c}-1.043^{* *} \\
0.192\end{array}$ \\
\hline Iname_5 & $\begin{array}{c}-0.608^{* *} \\
0.261\end{array}$ & $\begin{array}{c}-0.600 \\
0.431\end{array}$ & $\begin{array}{c}-0.767^{* *} \\
0.221\end{array}$ \\
\hline Iname_6 & $\begin{array}{c}0.745^{* *} \\
0.222\end{array}$ & $\begin{array}{c}1.298^{* * *} \\
0.403\end{array}$ & $\begin{array}{c}1.381^{* *} \\
0.185\end{array}$ \\
\hline Iname_7 & $\begin{array}{c}-0.831^{* *} \\
0.291\end{array}$ & $\begin{array}{c}-0.974^{* *} \\
0.466\end{array}$ & $\begin{array}{c}-0.875^{* *} \\
0.222\end{array}$ \\
\hline Iname_8 & $\begin{array}{c}0.050 \\
0.277\end{array}$ & $\begin{array}{l}0.332 \\
0.478\end{array}$ & $\begin{array}{l}0.122 \\
0.268\end{array}$ \\
\hline Iname_9 & $\begin{array}{c}-0.157 \\
0.281\end{array}$ & $\begin{array}{c}0.090 \\
0.489\end{array}$ & $\begin{array}{c}-0.094 \\
0.293\end{array}$ \\
\hline Iname_10 & $\begin{array}{c}0.662 * * \\
0.254\end{array}$ & $\begin{array}{c}0.754^{*} \\
0.469\end{array}$ & $\begin{array}{c}1.176^{* * *} \\
0.224\end{array}$ \\
\hline Iname_11 & $\begin{array}{c}-0.415^{*} \\
0.254\end{array}$ & $\begin{array}{c}-0.339 \\
0.416\end{array}$ & $\begin{array}{c}-0.526^{*} \\
0.206\end{array}$ \\
\hline
\end{tabular}

Table continued on next page 
Table A2. Household Size and Enumerator Effects for Hypothetical Vaccine Models (continued)

\begin{tabular}{lccc}
\hline Variable & Poisson & Negative Binomial & Truncated Poisson \\
\hline & & & \\
Iname_12 & -0.363 & -0.263 & -0.324 \\
& 0.293 & 0.477 & 0.248 \\
Iname_13 & $0.662^{* *}$ & $1.039^{* *}$ & $1.260^{* *}$ \\
& 0.250 & 0.451 & 0.211 \\
Iname_14 & $0.477^{* *}$ & $0.818^{*}$ & $0.863^{* *}$ \\
& 0.238 & 0.441 & 0.192 \\
Iname_16 & $-1.680^{* *}$ & $-1.485^{* *}$ & $-1.721^{* *}$ \\
& 0.459 & 0.603 & 0.338 \\
Iname_17 & -0.018 & -0.073 & 0.064 \\
& 0.236 & 0.409 & 0.196 \\
Iname_18 & 0.055 & 0.108 & 0.138 \\
& 0.268 & 0.452 & 0.212 \\
Iname_19 & $0.541^{* *}$ & $1.012^{* *}$ & $1.036^{* *}$ \\
& 0.239 & 0.439 & 0.188 \\
\hline
\end{tabular}

Notes: Standard errors in small font.

** Significant at the $5 \%$ level

* Significant at the $10 \%$ level 
Table A3. Means and Standard Deviations of Variables, Bednet Models

\begin{tabular}{lccccc}
\hline Variable & $\mathrm{N}$ & Mean & Std. Dev. & Min & Max \\
\hline Number of nets purchased & 279 & 1.07 & 1.14 & 0 & 9 \\
Price (Birr) & 279 & 44.89 & 32.78 & 8 & 100 \\
Log income (Thousand Birr) & 279 & 1.97 & 1.23 & -4 & 4 \\
Missing wage (1 if no wage) & 279 & 0.39 & 0.49 & 0 & 1 \\
Number teenagers & 279 & 0.56 & 0.78 & 0 & 4 \\
Number of children & 279 & 1.74 & 1.33 & 0 & 5 \\
Household cost of illness (Birr) & 279 & 22.26 & 16.45 & 0 & 97 \\
Married (1 if married) & 279 & 0.70 & 0.46 & 0 & 1 \\
Gender (1 if female) & 279 & 0.66 & 0.47 & 0 & 1 \\
Read (1 if read easily) & 279 & 0.53 & 0.50 & 0 & 1 \\
Age (years) & 279 & 41.04 & 15.04 & 16 & 80 \\
Alt (hundred meters) & 279 & 16.51 & 1.89 & 12 & 19 \\
Household size & 279 & 4.53 & 2.03 & 1 & 12 \\
\hline
\end{tabular}


Table A3. Means and Standard Deviations of Variables, Bednet Models (continued)

\begin{tabular}{|c|c|c|c|c|c|}
\hline Variable & Obs & Mean & Std. Dev. & Min & Max \\
\hline$\overline{\text { HSIZE2 }}$ & 279 & 0.13 & 0.33 & 0 & 1 \\
\hline HSIZE3 & 279 & 0.15 & 0.35 & 0 & 1 \\
\hline HSIZE4 & 279 & 0.21 & 0.41 & 0 & 1 \\
\hline HSIZE5 & 279 & 0.18 & 0.38 & 0 & 1 \\
\hline HSIZE6 & 279 & 0.12 & 0.33 & 0 & 1 \\
\hline HSIZE7 & 279 & 0.11 & 0.31 & 0 & 1 \\
\hline HSIZE8 & 279 & 0.04 & 0.19 & 0 & 1 \\
\hline HSIZE9 & 279 & 0.03 & 0.17 & 0 & 1 \\
\hline Inam_2 & 279 & 0.06 & 0.24 & 0 & 1 \\
\hline Inam_3 & 279 & 0.08 & 0.26 & 0 & 1 \\
\hline Inam_4 & 279 & 0.00 & 0.00 & 0 & 0 \\
\hline Inam_5 & 279 & 0.00 & 0.00 & 0 & 0 \\
\hline Inam_6 & 279 & 0.00 & 0.00 & 0 & 0 \\
\hline Inam_7. & 279 & 0.00 & 0.00 & 0 & 0 \\
\hline Inam_8 & 279 & 0.08 & 0.28 & 0 & 1 \\
\hline Inam_9 & 279 & 0.09 & 0.29 & 0 & 1 \\
\hline Inam_10 & 279 & 0.09 & 0.28 & 0 & 1 \\
\hline Inam_11 & 279 & 0.00 & 0.06 & 0 & 1 \\
\hline Inam_12 & 279 & 0.08 & 0.27 & 0 & 1 \\
\hline Inam_13 & 279 & 0.08 & 0.27 & 0 & 1 \\
\hline Inam_14 & 279 & 0.09 & 0.29 & 0 & 1 \\
\hline Inam_16 & 279 & 0.08 & 0.28 & 0 & 1 \\
\hline Inam_17 & 279 & 0.00 & 0.06 & 0 & 1 \\
\hline Inam_18 & 279 & 0.09 & 0.29 & 0 & 1 \\
\hline Inam 19 & 279 & 0.09 & 0.28 & 0 & 1 \\
\hline
\end{tabular}


Table A4. Household Size and Enumerator Effects for Bednet Models

\begin{tabular}{|c|c|c|c|}
\hline Variable & Poisson & Negative Binomial & Truncated Poisson \\
\hline DIhh_2 & $\begin{array}{c}-0.227 \\
0.446\end{array}$ & $\begin{array}{c}-0.227 \\
0.447\end{array}$ & $\begin{array}{l}-0.971 \\
0.732\end{array}$ \\
\hline DIhh_3 & $\begin{array}{c}0.230 \\
0.442\end{array}$ & $\begin{array}{c}0.230 \\
0.443\end{array}$ & $\begin{array}{c}-0.626 \\
0.709\end{array}$ \\
\hline DIhh_4 & $\begin{array}{c}-0.239 \\
0.482\end{array}$ & $\begin{array}{c}-0.239 \\
0.483\end{array}$ & $\begin{array}{l}-1.256 \\
0.733\end{array}$ \\
\hline DIhh_5 & $\begin{array}{c}0.101 \\
0.523\end{array}$ & $\begin{array}{c}0.101 \\
0.523\end{array}$ & $\begin{array}{c}-0.914 \\
0.794\end{array}$ \\
\hline DIhh_6 & $\begin{array}{l}0.367 \\
0.563\end{array}$ & $\begin{array}{c}0.367 \\
0.563\end{array}$ & $\begin{array}{c}-0.628 \\
0.866\end{array}$ \\
\hline DIhh_7 & $\begin{array}{c}0.296 \\
0.641\end{array}$ & $\begin{array}{c}0.296 \\
0.641\end{array}$ & $\begin{array}{c}-0.714 \\
0.959\end{array}$ \\
\hline DIhh_8 & $\begin{array}{l}0.110 \\
0.732\end{array}$ & $\begin{array}{c}0.110 \\
0.730\end{array}$ & $\begin{array}{c}-0.876 \\
1.089\end{array}$ \\
\hline DIhh_9 & $\begin{array}{l}0.885 \\
0.802\end{array}$ & $\begin{array}{l}0.885 \\
0.802\end{array}$ & $\begin{array}{c}-0.039 \\
1.192\end{array}$ \\
\hline Iname_2 & $\begin{array}{c}-0.203 \\
0.319\end{array}$ & $\begin{array}{c}-0.203 \\
0.319\end{array}$ & $\begin{array}{c}-0.202 \\
0.409\end{array}$ \\
\hline Iname 3 & $\begin{array}{c}0.500^{*} \\
0.278\end{array}$ & $\begin{array}{c}0.500^{*} \\
0.277\end{array}$ & $\begin{array}{c}0.588^{*} \\
0.347\end{array}$ \\
\hline Iname_8 & $\begin{array}{l}0.126 \\
0.302\end{array}$ & $\begin{array}{l}0.126 \\
0.302\end{array}$ & $\begin{array}{c}0.126 \\
0.373\end{array}$ \\
\hline Iname_9 & $\begin{array}{c}0.430 \\
0.303\end{array}$ & $\begin{array}{c}0.430 \\
0.304\end{array}$ & $\begin{array}{c}0.439 \\
0.386\end{array}$ \\
\hline Iname_10 & $\begin{array}{l}-0.064 \\
0.331\end{array}$ & $\begin{array}{c}-0.064 \\
0.332\end{array}$ & $\begin{array}{c}-0.123 \\
0.430\end{array}$ \\
\hline Iname_12 & $\begin{array}{c}-0.784^{* *} \\
0.368\end{array}$ & $\begin{array}{c}-0.784^{*} \\
0.367\end{array}$ & $\begin{array}{c}-0.838^{* *} \\
0.408\end{array}$ \\
\hline Iname_13 & $\begin{array}{c}-0.059 \\
0.333\end{array}$ & $\begin{array}{c}-0.059 \\
0.333\end{array}$ & $\begin{array}{c}-0.090 \\
0.460\end{array}$ \\
\hline Iname_14 & $\begin{array}{c}0.412 \\
0.266\end{array}$ & $\begin{array}{c}0.412 b \\
0.266\end{array}$ & $\begin{array}{c}0.512 \\
0.337\end{array}$ \\
\hline Iname_16 & $\begin{array}{c}-0.916^{* *} \\
0.408\end{array}$ & $\begin{array}{c}-0.916^{* *} \\
0.407\end{array}$ & $\begin{array}{c}-1.052^{* *} \\
0.463\end{array}$ \\
\hline Iname_18 & $\begin{array}{c}-0.135 \\
0.336\end{array}$ & $\begin{array}{c}-0.135 \\
0.337\end{array}$ & $\begin{array}{c}-0.185 \\
0.405\end{array}$ \\
\hline Iname_19 & $\begin{array}{l}-0.032 \\
0.305\end{array}$ & $\begin{array}{l}-0.032 \\
0.305\end{array}$ & $\begin{array}{c}-0.091 \\
0.445\end{array}$ \\
\hline
\end{tabular}

Notes: Standard errors in small font.

${ }^{* *}$ Significant at the $5 \%$ level

* Significant at the $10 \%$ level 



\section{Policy Research Working Paper Series}

Title

WPS2252 Productivity Growth, Capital Accumulation, and the Banking Sector: Some Lessons from Malaysia

WPS2253 Revenue Recycling and the Welfare Effects of Road Pricing

WPS2254 Does "Grease Money" Speed Up the Wheels of Commerce?

WPS2255 Risk and Efficiency in East Asian Banks

WPS2256 Geographical Disadvantage: A Heckscher-Ohlin-von Thunen Model of International Specialization

WPS2257 Infrastructure, Geographical Disadvantage, and Transport Costs

WPS2258 Market Access Bargaining in the Uruguay Round: Rigid or Relaxed Reciprocity?

WPS2259 Predicting Currency Fluctuations and Crises: Do Resident Firms Have an Informational Advantage?

WPS2260 Regional Integration Agreements: A Force for Convergence or Divergence?

WPS2261 is Knowledge Shared within Households?

WPS2262 How Inadequate Provision of Public Infrastructure and Services Affects Private Investment

WPS2263 When Is Growth Pro-Poor? Evidence from the Diverse Experiences of India's States

WPS2264 Do More Unequal Countries Redistribute More? Does the Median Voter Hypothesis Hold?

\section{Author}

Ejaz Ghani

Vivek Suri

lan W. H. Parry

Antonio Miguel R. Bento

Daniel Kaufmann

Shang-Jin Wei

Luc Laeven

Anthony J. Venables

Nuno Limão

Nuno Limão

Anthony J. Venables

J. Michael Finger

Ulrich Reincke

Adriana Castro

Daniel Kaufmann

Gil Mehrez

Sergio Schmukler

Anthony J. Venables

Kaushik Basu

Ambar Narayan

Martin Ravallion

Ritva Reinikka

Jakob Svensson

Martin Ravallion

Gaurav Datt

Branko Milanovic
Date

December 1999

December 1999

December 1999

December 1999

December 1999

December 1999

December 1999

December 1999

December 1999

December 1999

December 1999

December 1999
M. Mason 30809

J. Israel 85117

Contact for paper

N. Mensah 80546

R. Yazigi 37176

H. Sladovich 37698

R. Vo 33722

L. Tabada 36896

L. Tabada 36896

L. Tabada 36896

E. Khine 37471

L. Tabada 36896

H. Sladovich 37698

P. Sader 33902 


\section{Policy Research Working Paper Series}

\begin{tabular}{|c|c|c|c|c|}
\hline & Title & Author & Date & $\begin{array}{l}\text { Contact } \\
\text { for paper }\end{array}$ \\
\hline WPS2265 & $\begin{array}{l}\text { The Political Economy of Distress } \\
\text { In East Asian Financial Institutions }\end{array}$ & $\begin{array}{l}\text { Paola Bongini } \\
\text { Stijn Claessens } \\
\text { Giovanni Ferri }\end{array}$ & January 2000 & $\begin{array}{l}\text { R. Vo } \\
33722\end{array}$ \\
\hline WPS2266 & $\begin{array}{l}\text { The Impact of Adult Deaths on } \\
\text { Children's Health in Northwestern } \\
\text { Tanzania }\end{array}$ & $\begin{array}{l}\text { Martha Ainsworth } \\
\text { Innocent Semali }\end{array}$ & January 2000 & $\begin{array}{l}\text { S. Fallon } \\
38009\end{array}$ \\
\hline WPS2267 & $\begin{array}{l}\text { Do High Interest Rates Defend } \\
\text { Currencies during Speculative Attacks? }\end{array}$ & Aart Kraay & January 2000 & $\begin{array}{l}\text { R. Bonfield } \\
31248\end{array}$ \\
\hline WPS2268 & $\begin{array}{l}\text { The Structure of Social Disparities } \\
\text { In Education: Gender and Wealth }\end{array}$ & Deon Filmer & January 2000 & $\begin{array}{l}\text { S. Fallon } \\
38009\end{array}$ \\
\hline WPS2269 & $\begin{array}{l}\text { Context is Everything: Measuring } \\
\text { Institutional Change in Transition } \\
\text { Economies }\end{array}$ & Nauro F. Campos & January 2000 & $\begin{array}{l}\text { J. Victor } \\
36549\end{array}$ \\
\hline WPS2270 & $\begin{array}{l}\text { The Optimal Income Tax When } \\
\text { Poverty Is a Public "Bad" }\end{array}$ & Waly Wane & January 2000 & $\begin{array}{l}\text { H. Sladovich } \\
37698\end{array}$ \\
\hline WPS2271 & Corporate Risk around the World & $\begin{array}{l}\text { Stijn Claessens } \\
\text { Simeon Djankov } \\
\text { Tatiana Nenova }\end{array}$ & January 2000 & $\begin{array}{l}\text { R. Vo } \\
33722\end{array}$ \\
\hline WPS2272 & $\begin{array}{l}\text { Ownership versus Environment: } \\
\text { Disentangling the Sources of Public } \\
\text { Sector Inefficiency }\end{array}$ & $\begin{array}{l}\text { Ann P. Bartel } \\
\text { Ann E. Harrison }\end{array}$ & January 2000 & $\begin{array}{l}\text { S. Fallon } \\
38009\end{array}$ \\
\hline
\end{tabular}

